\title{
A new route for the synthesis of self-acidified and granulated mesoporous alumina catalyst with superior Lewis acidity and its application in cumene conversion
}

\author{
Mohsen S. Mostafa ${ }^{1}$, Ahmed O. Abo El Naga ${ }^{1}$, Ahmed A. Galhoum ${ }^{2}$, Eric Guibal ${ }^{3, \star}$, and \\ Asmaa S. Morshedy ${ }^{1, *}$ \\ ${ }^{1}$ Refining Division, Egyptian Petroleum Research Institute, Nasr City, Cairo 11727, Egypt \\ ${ }^{2}$ Nuclear Materials Authority, P.O. Box 530, El-Maadi, Cairo, Egypt \\ ${ }^{3}$ IMT - Mines Ales, Centre des Matériaux des Mines d'Alès, Univ Montpellier, 6 avenue de Clavières, 30319 Alès Cedex, France
}

\begin{abstract}
Self-acidified and granulated mesoporous alumina (SAGMA) with dendritic-like microscopic shape was prepared by a new route that involves: (a) direct dehydration of $\mathrm{AlCl}_{3}$ (in the presence of capping petroleum wax), and (b) oxi-dation of intermediary $\mathrm{AlCl}_{3}$-nanorods. The $\mathrm{AlCl}_{3}$ solution dispersed in petro-leum wax (capping media) was firstly dehydrated at $100{ }^{\circ} \mathrm{C}$ under inert atmosphere for manufacturing anhydrous $\mathrm{AlCl}_{3}$-nanorods (length: 50-100 nm; diameter: 5-10 nm). In a second step, this support was oxidized into $\gamma$-alumina at $300^{\circ} \mathrm{C}$, under air atmosphere. In the course of the manufacturing process, released chlorine was deposited at the surface of the nanorods (more specifically during the oxidation step). The binding of chlorine $(5.35 \%, \mathrm{w} / \mathrm{w}$ at the surface) onto $\gamma$-alumina was demonstrated by both electron dispersive X-ray analysis (SEM-EDX) and Fourier-transformed infrared spectroscopy. Specific surface area reached $230 \mathrm{~m}^{2} \mathrm{~g}^{-1}$; the average pore size was $7.8 \mathrm{~nm}$. Material charac-terization was completed by measuring the surface acidity through both tem-perature-programmed desorption and pyridine desorption. The morphology and the phase structure were investigated using scanning electron microscopy and X-ray diffraction analysis, respectively. SAGMA ( $\gamma$-alumina) can be described as a strong Lewis (1.713 $\mathrm{mmol} \mathrm{g}^{-1}$; i.e., about $93 \%$ of total acid sites) and Brønsted acid catalyst supported on a mesoporous structure (self-granular size of 177-250 $\mu \mathrm{m}$ ). Cumene conversion (through a dealkylation pathway) was tested on SAGMA: maximum catalytic activity reached $87 \%$ at $300{ }^{\circ} \mathrm{C}$. The conversion is highly selective: the reaction produces benzene and only traces of ethylbenzene (mass fraction below $4 \%$ compared to benzene). Apart from this good catalytic efficiency, the material is characterized by its strong stability in terms of both catalytic activity (loss less than $2 \%$, for optimum conditions) and surface acidity (loss less than 3\%), even for long reaction times (i.e., $24 \mathrm{~h}$ ) under severe conditions (i.e., $\mathrm{T} 300{ }^{\circ} \mathrm{C}$ ). This new material, easily manufactured, is characterized by high efficiency and selectivity in cumene conversion into benzene, associated with high acidity and good stability
\end{abstract}

Address correspondence to E-mail: Eric.Guibal@mines-ales.fr; asma_2000asma@yahoo.com 


\section{Introduction}

Catalysis and catalytic materials play an essential role in chemistry and chemical industries. In the last decades, the industrial activities were greatly developed to fulfill the increasing demand of the growing population; many chemical reactions were intensified in fields of petrochemical, agriculture, pharmaceuti$\mathrm{cal}$, and food industries. To achieve these targets, the chemical reactions involve different types of catalytic materials; in order to save catalytic metal and Cocatalysts, heterogeneous catalysis has retained an increasing attention from research community. Specific applications have been designed using supports as zeolite [1-5], tungstate/niobate [6], zirconia [7], silica [8, 9], nickel [10], alumina [11], aluminosilicates [9, 12, 13], and layered double hydroxides (LDHs) [14, 15]. Alumina is one of the most applied material for designing sorbents and catalysts because of its wide availability, high thermal stability, high mechanical strength, and large versatility (several phases and tailored structures can be produced for facing specific applications and requirements). In addition, parameters such as high surface areas, ready ability to form binary or mixed metal oxides and composites, versatile acid-base properties can explain the attention paid to alumina-based catalytic supports [16-21]. Alumina was widely applied as an adsorbent for gas [22] and for different organic [23] and inorganic pollutants [24, 25], as a "direct" catalyst for many chemical reactions [26], but also extensively used as a support for many catalytic materials [27].

Gamma $(\gamma)$-alumina is a well-known phase of alumina with characteristic physicochemical properties that made this structured material one of the most applied in various chemical reactions. The potential features of $\gamma$-alumina phase are originated from its unique structure; its cubic defect of spinel type is due to the specific organization of $\mathrm{Al}$ atoms located on octahedral and tetrahedral sites with scattered vacancies distributed on both the two sites.
This is giving to $\gamma$-alumina its specific surface properties: high surface area and acidity. Several methods can be used for managing the surface properties of $\gamma$ alumina, for example playing with the temperature of calcination [28], the digestion of the aluminum hydroxide precursor [29], or the incorporation of a template $[22,30]$. The acidity of $\gamma$-alumina is a very crucial parameter that plays an effective role in many catalytic reactions as isomerization [31], hydrocracking [32], hydrogenation-dehydrogenation reactions [33], and dehydration [12]. For Si/Al catalysts obtained by calcination of SBA-15 and Al-SBA-15 (prepared with different $\mathrm{Si} / \mathrm{Al}$ ratios), the activity of the catalysts for cumene conversion was perfectly correlated with the total acidity of the material [34]. The incorporation of aluminum on silica support (using anionic surfactant as template) contributes to control the Brønsted acid sites that will be active for cumene conversion [35].

Accordingly, extensive research and diverse routes were applied to controlling and making use of this acidic property by:

1. Incorporation of foreign atoms or elements into $\gamma$ alumina "building" under controlled conditions creating reliant composition enriched with labile hydrogen through the hydrogen bonding, or atoms and elements that can have different or similar valances than that of alumina; this may be silica [12], phosphorous [36], titanium [37], and zirconium [7].

2. Acidification of manufactured $\gamma$-alumina with mineral acids as $\mathrm{HF}, \mathrm{HCl}, \mathrm{H}_{3} \mathrm{PO}_{4}$, and $\mathrm{H}_{2} \mathrm{SO}_{4}$ or by acid bearing conjugated bases as $\mathrm{NH}_{4} \mathrm{Cl}$ and $\mathrm{NH}_{4} \mathrm{~F}[8,38-40]$.

3. Incorporation of $\mathrm{Cl}$ or $\mathrm{F}$ onto alumina during its preparation by precipitation of alumina from acidic solution [41].

The former route may be seen as most operative and practical due to the remarkable stability of produced alumina and the simultaneous incorporation of the acidic radicals $(\mathrm{Cl}$ or $\mathrm{F})$ during the proper 
manufacturing procedure. Previous studies showed that the acidification of alumina with sulfuric acid leads, in practice, to more stable materials than chlorinated alumina; this is due to the readily displacement of incorporated chlorine and the progressive lowering of acidity [42]. In this work, an innovative route is designed for the synthesis of selfacidified and granulated mesoporous alumina (herein called SAGMA) directly from the $\mathrm{AlCl}_{3}$ solution under moderate temperatures $\left(100-300{ }^{\circ} \mathrm{C}\right)$ in the presence of petroleum wax as a capping media. According to this method, $\mathrm{AlCl}_{3}$ solution was firstly dehydrated at low temperature $\left(100{ }^{\circ} \mathrm{C}\right)$ in the presence of a capping media, under nitrogen atmosphere with vigorous stirring. As a result of this first step, $\mathrm{AlCl}_{3}$-nanorods were produced; HRTEM was used for characterizing the shape of these intermediary objects. In the second step of the process, in a closed system, the $\mathrm{AlCl}_{3}$-nanorods were oxidized under air atmosphere, at $300{ }^{\circ} \mathrm{C}$; the closed reactor contributes to "recycling" chlorine (under the form of $\mathrm{Cl}$ and/or $\mathrm{HCl}$ ) by deposition at the surface of produced $\gamma$ alumina. This direct acidification of $\gamma$-alumina by self-chlorination in the course of catalyst manufacturing overcomes many conventional steps and drawbacks frequently encountered in the synthesis of acidic $\gamma$-alumina, such as (a) long reaction time of designing, (b) using precipitating agents, (c) applying external acidifying agents, and (d) processing the calcination at elevated temperatures $\left(500-700{ }^{\circ} \mathrm{C}\right)$.

The physical and chemical properties of the material were investigated using SEM observations, SEMEDX, XRD, DSC and TGA analyses, surface area and porosimeter measurements, FTIR spectroscopy, temperature-programmed desorption and pyridine desorption (for determination of acidic properties). In a second step, the catalyst was used for the dealkylation of cumene, paying attention to (a) the effect of temperature on the rate of conversion to benzene (with identification of other sub-products) in function of the LHSV (i.e., liquid hourly space velocity: reactant flow rate/reactor volume) and (b) the effect of long use of the catalyst (for evaluating the effect of aging at different temperatures and for 2 values of LHSV). Cumene conversion has been frequently operated using $\gamma$-alumina [43, 44].

Another expected benefit of the process consists of the self-structuration of the material for forming granular particles of size ranging between 170 and $250 \mu \mathrm{m}$ (60-80 mesh). This size of catalyst particles allows its use without further need of pelletization. This was the case in the present study where the catalyst was used as produced for cumene cracking and conversion to benzene.

\section{Materials and methods}

\section{Materials and chemicals}

Anhydrous aluminum trichloride $\left(\mathrm{AlCl}_{3},<99 \%\right)$ was purchased from Merck; n-heptane $(<99 \%)$ and cumene (98\%) were purchased from Sigma-Aldrich. Finally, petroleum macro-crystalline wax was obtained as aside by-product from Al-Amerya Petroleum Company (Egypt). The wax is characterized by an initial boiling point close to $40-45^{\circ} \mathrm{C}$. It is characterized by saturated hydrocarbons (with a weight percentage close to $90 \%$ ), including n-paraffin (15\%) and iso- or cycloparaffins (75\%), while $10 \%$ is constituted of mono-aromatics.

\section{Preparation of self-acidified and granulated gamma alumina (SAGMA)}

The preparation of SAGMA was achieved through two steps: (a) the dehydration of $\mathrm{AlCl}_{3}$ solution to anhydrous $\mathrm{AlCl}_{3}$-nanorods in a capping media of petroleum wax under inert atmosphere and then (b) oxidation of the prepared nanorods by air in a closed reactor cycle, allowing the recycling and deposition of the chlorides released from the preparation media at the surface of nanorods. A specific reactor was designed (Fig. 1).

\section{Dehydration step}

First, a homogeneous solution was prepared by mixing $15 \mathrm{~g} \mathrm{AlCl}_{3}, 150 \mathrm{~mL} \mathrm{H}_{2} \mathrm{O}$, and $100 \mathrm{~g}$ microcrystalline wax at $45{ }^{\circ} \mathrm{C}$ under vigorous stirring for $1 \mathrm{~h}$. The solution was then transferred into a Pyrex reactor $(30 \mathrm{~cm} \mathrm{~L} \times 10 \mathrm{~cm}$ i.d.) placed over a thermally controlled hot plate magnetic stirrer; the reactor was connected to a $\mathrm{N}_{2}$ cylinder on the one side and to a circulating pump at the other side. The dehydration of $\mathrm{AlCl}_{3}$ solution (converted into $\mathrm{AlCl}_{3}$ nanorods) was achieved by rising the temperature of the $\mathrm{AlCl}_{3}$ solution-petroleum wax system to 100 $( \pm 5){ }^{\circ} \mathrm{C}$ for $3 \mathrm{~h}$ under $\mathrm{N}_{2}$ atmosphere, and strong agitation. The condensed water vapor was collected 


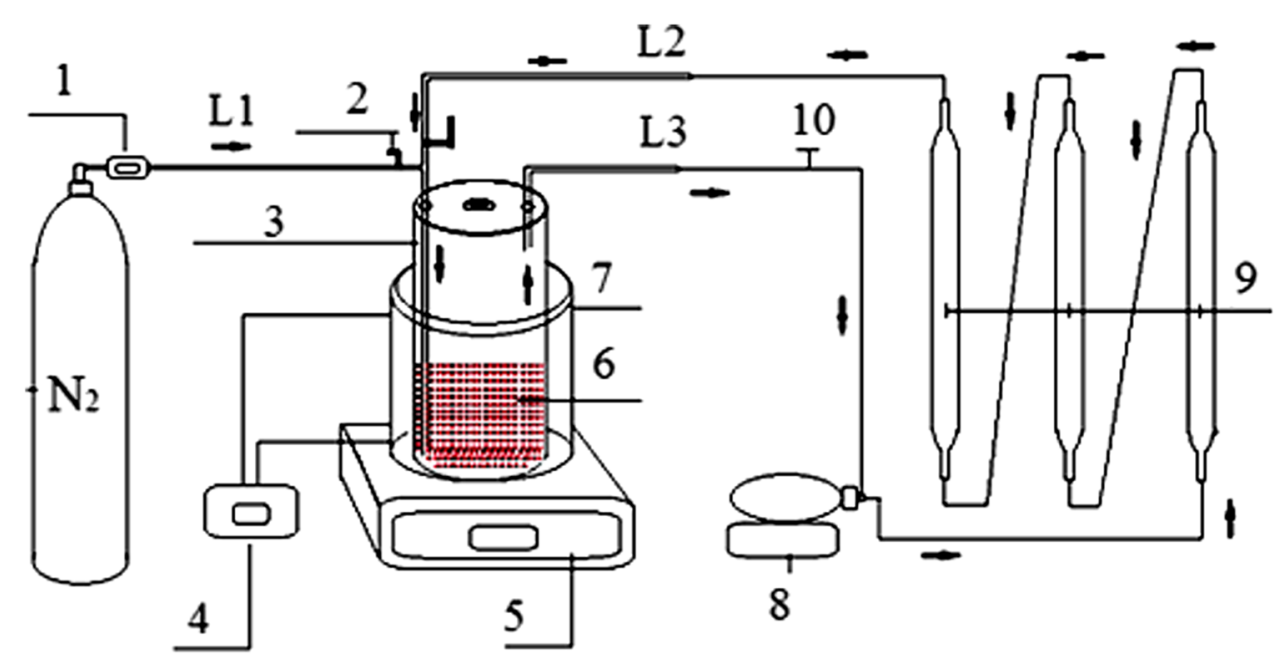

Figure 1 Experimental platform, especially designed for the synthesis of this mesoporous $\gamma$-alumina (1: mass flow controller, 2: controlling valve, 3: pyrex reactor, 4: pyrometer, 5: hot plate magnetic stirrer, 6: $\mathrm{AlCl}_{3}$ solution-petroleum wax mixture, 7: glass

through line 3 (Fig. 1). After complete dehydration, the stirring was stopped and a sample was collected out for analysis.

\section{Oxidation and self-chlorination step}

The self-chlorination and oxidation of the prepared $\mathrm{AlCl}_{3}$-nanorods into $\gamma$-alumina was performed by disconnecting the $\mathrm{N}_{2}$ line, rising the temperature to $300{ }^{\circ} \mathrm{C}$ and turning on the circulating pump to recycle the released chlorides together with sufficient air, which was supplied by three glass columns $(100 \mathrm{~cm}$ $\mathrm{L} \times 5 \mathrm{~cm}$ i.d.) connected to the reaction media. The oxidation process was completed within $1 \mathrm{~h}$. The system was allowed to cool down to $45{ }^{\circ} \mathrm{C}$, ventilating the excess of chlorine into $1 \mathrm{M} \mathrm{NaOH}$ solution (for neutralization) The $\gamma$-alumina granules were washed by $\mathrm{n}$-heptane several times before being finally dried at $120^{\circ} \mathrm{C}$ for $1 \mathrm{~h}$. The catalysts were systematically freshly prepared (about $1 \mathrm{~h}$ ) before use.

\section{Catalytic activity measurements}

A fixed-bed flow reactor (quartz reactor; $10 \mathrm{~mm}$ i.d. $\times 30 \mathrm{~cm}$ length) was used to study the catalytic activity of the prepared mesoporous $\gamma$-alumina toward cumene conversion at atmospheric pressure and inert $\mathrm{N}_{2}$ gas. The reactor was adapted to the setup of online GC fixed-bed flow system (used for all catalytic activity measurements). The SAGMA

jacket, 8: circulating pump, 9: three glass columns $(100 \mathrm{~cm}$ $\mathrm{L} \times 5 \mathrm{~cm}$ i.d.) 10: controlling valve-L1: $\mathrm{N}_{2}$ gas line, $\mathrm{L} 2$ : airchlorides mixture pumping line into the preparation system, L3: for condensation and suction of air-chlorides mixture.).

catalyst powder is characterized by a granular size close to $250 \mu \mathrm{m}$ (and a specific surface area close to $230 \mathrm{~m}^{2} \mathrm{~g}^{-1}$ ); an amount of $1 \mathrm{~g}$ of catalyst was sufficient to occupy a column depth close to $3-3.5 \mathrm{~cm}$ (without pilled quart dilution). The active catalytic bed was located in the middle part of the column (corresponding to the 10-cm-length central zone of the column). The top and bottom parts $(20 \mathrm{~cm}$ length) were partially or fully filled with fine-pilled quartz particles, and they served as pre- and postheating zones, respectively. This experimental setup allowed getting a continuous flow of both $\mathrm{N}_{2}$ and cumene vapors during the complete kinetic experiments. The sample of $1 \mathrm{~g}$ alumina was introduced and activated at $360{ }^{\circ} \mathrm{C}$ for $1 \mathrm{~h}$ under $\mathrm{N}_{2}$ (flow rate $10 \mathrm{~mL} \mathrm{~min}{ }^{-1}$ ). After activation and cooling down to $100{ }^{\circ} \mathrm{C}$, cumene was introduced into the reaction system by a micro-dosing pump at a temperature range from 150 to $360{ }^{\circ} \mathrm{C}$ and liquid hourly space velocities (LHSV) were 2 and $4 \mathrm{~h}^{-1}$. The outlet products from the reaction system were analyzed by online gas chromatograph GC using Agilent (7890 A) GC (Agilent Technologies, Wilmington, DE, USA) equipped with the hp-5 column and a flame ionization detector (FID). Experiments were triplicated for the evaluation of cumene conversion, which was calculated according to Eq. (1):

Total conversion of cumene $(\%)$

$$
=\frac{(\text { Cum.i-Cum.t })}{\text { Cum.i }} \times 100 \text {. }
$$




\section{Material characterization}

The diffraction patterns of the prepared alumina were recorded using an X-ray diffractometer (XRD Bruker AXS-D8 Advance, Bruker, Karlsruhe, Germany) with nickel-filtered copper radiation $(\lambda=1.5405 \AA)$ for $2 \theta$ angle varying between $2^{\circ}$ and $70^{\circ}$. Differential scanning calorimetry (DSC) and thermal gravimetric analysis (TGA) were performed on SDT-Q 600 V20.5 Build 15 apparatus (TA Instruments, Eschborn, Germany). The surface area was measured with $\mathrm{N}_{2}$ adsorption-desorption isotherms acquired on a Quantachrome Nova 3200 instrument (Boynton Beach, FL, USA) under a degassing temperature of $300{ }^{\circ} \mathrm{C}$, while the pore volume was measured according to the BJH method. The FTIR spectra were recorded on ATI Mattson Genesis series $(\mathrm{KBr}$ disk method) (Mattson Instruments, Inc., Madison, WI, USA). The acidity measurements of the prepared alumina were obtained by both temperature-programmed desorption (TPD) in an automated BEL CAT instrument (MicrotracBEL Corp., Osaka, Japan) equipped with a TCD detector and FTIR analysis of adsorbed pyridine. In the case of pyridine detection by FTIR, a sample of alumina granules (60-80 mesh) was firstly activated under vacuum at $300{ }^{\circ} \mathrm{C}$ for $2 \mathrm{~h}$, the adsorption of pyridine vapors was performed at $150{ }^{\circ} \mathrm{C}$ for $15 \mathrm{~min}$ with $\mathrm{N}_{2}$ flow rate of $10 \mathrm{~mL} \mathrm{~min}{ }^{-1}$, while the desorption of physically adsorbed molecules was continued for $2 \mathrm{~h}$ under selected conditions. Scanning electron microscope (JEOL 5300, JEOL Ltd., Tokyo, Japan) was used for characterizing the surface morphology of the sample. The deep morphology of the material was observed using a high-resolution transmission electron microscope (HRTEM) (JEOL 1230, JEOL Ltd., Tokyo, Japan); the coupling with energy-dispersive X-ray analysis (EDX) (X-Max model, Oxford Instruments, Abingdon, Oxfordshire, UK) allowed identifying the presence of chloride on the catalyst.

\section{Results and discussion}

\section{Characterizations of materials}

$X R D$ analysis

Figure AM1 (see Additional Material Section) shows the XRD patterns of the prepared alumina. The cubic $\gamma$-alumina phase of the catalyst is characterized by the presence of peaks at $2 \theta$ angles of $20.0^{\circ}, 31.7^{\circ}$, $37.0^{\circ}, 39.7^{\circ}, 45.5^{\circ}, 60.0^{\circ}$, and $67.0^{\circ}$, which are assigned to the planes (111), (220), (311), (222), (400), (511), and (440), respectively, according to JCPDS card No. 10-0425 [45]. The distortion and broadness of detected peaks that give to the XRD pattern the behavior of an amorphous structure to synthesized $\gamma$-alumina can be explained by the tiny (nanometer) size of crystals (i.e., less than $5 \mathrm{~nm}$ ) [24]. The temperature used for synthesis procedure is low enough to prevent the formation of $\alpha$-alumina (which may appear at temperature above $\left.700{ }^{\circ} \mathrm{C}[20]\right)$. However, with a reference temperature of $300{ }^{\circ} \mathrm{C}$ for the synthesis procedure, this may contribute to less resolved XRD diffraction patterns as observed in the synthesis of flowerlike $\gamma$-alumina grown by precipitation on quartz surface at high temperatures [17]. In the case of the synthesis of $\gamma$-alumina by hydrolysis of aluminum isopropoxide, Dabbagh et al. [46] reported that the broadness of the peaks can be also explained by the random distribution of aluminum ions over the tetrahedron sites of the spinel lattice [47].

\section{FTIR spectrometry}

The FTIR spectra of synthesized $\gamma$-alumina, conventional alumina (aluminum hydroxide prepared by conventional precipitation with sodium hydroxide at room temperature), and pyridine-adsorbed species on synthesized $\gamma$-alumina are shown in Fig. 2. Aluminum hydroxide (freshly prepared) was used as simulate of the intermediary product in the conventional method of synthesis of $\gamma$-alumina (i.e., alumina hydroxide precipitation followed by dehydration and calcination). For the conventional alumina, a strong and broad band is appearing in the range $3800-3450 \mathrm{~cm}^{-1}$; this band is associated with water molecules adsorbed on the surface of alumina; in addition, a peak located at $3790 \mathrm{~cm}^{-1}$ (masked by the water signal) is usually assigned to $-\mathrm{OH}$ band. For the synthesized mesoporous $\gamma$-alumina, the band is considerably weakened; this is directly attributable to the substitution of $-\mathrm{OH}$ groups with $\mathrm{Cl}$ through the acidification of alumina surface and the recycling of chloride/chlorine compound released from $\mathrm{AlCl}_{3}$ nanorods during the oxidation step. The substitution of $\mathrm{OH}$ groups with chloride was already reported by 
Figure 2 FTIR spectra of conventional alumina (A), mesoporous $\gamma$-alumina (B, synthesized in this study), and mesoporous $\gamma$-alumina loaded with pyridine $(\mathrm{C})$ : a full spectra, b hydroxyl group area-focused spectra,

c pyridine-sorbed catalyst with focus on identification of reactive groups (indices: $\mathrm{B}$ for Brønsted acid sites, L for Lewis acid sites, $\mathrm{P}$ for pyridine/pyridinium bands, $\mathrm{H}$ for H-bonded species) [43]).
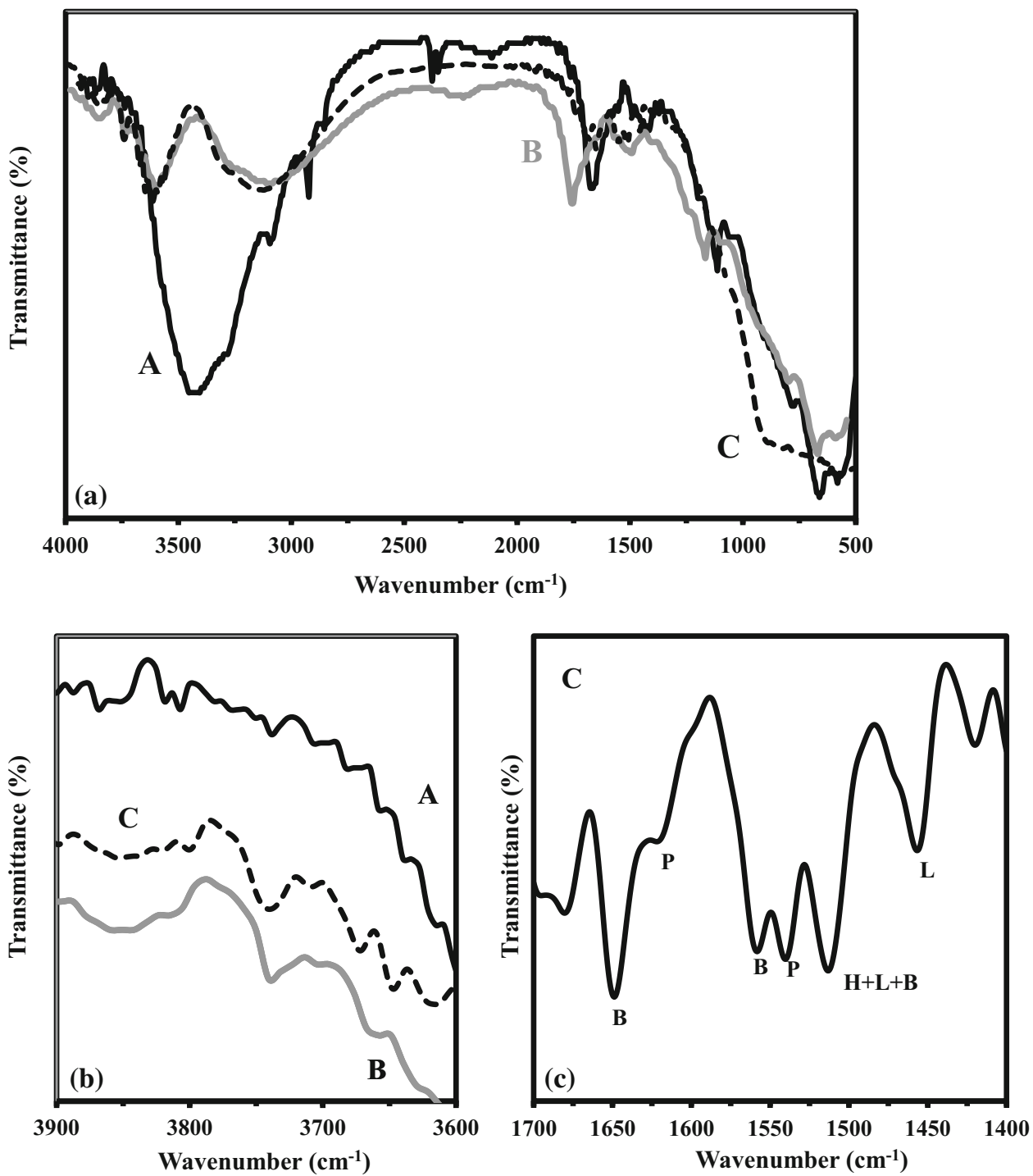

Kytökivi according to the following mechanism [48]:<smiles>O[14CH2][14CH](Cl)[14CH2]O</smiles>

Actually, it is suspected that dehydration of $\mathrm{AlCl}_{3}$ is incomplete and the following steps are proposed for the elaboration of the catalyst and more specifically the self-chlorination of the catalyst in the closed reactor:

$$
\begin{aligned}
& \mathrm{AlCl}_{3}, 6 \mathrm{H}_{2} \mathrm{O} \stackrel{100{ }^{\circ} \mathrm{C}, \mathrm{N}_{2}}{\longrightarrow} \mathrm{AlCl}_{3}, \frac{6}{n} \mathrm{H}_{2} \mathrm{O}+\mathrm{H}_{2} \mathrm{O} \uparrow \\
& \mathrm{AlCl}_{3}, \frac{6}{n} \mathrm{H}_{2} \mathrm{O} \stackrel{30{ }^{\circ} \mathrm{C}, \mathrm{Air}}{\longrightarrow} \mathrm{Al}_{2} \mathrm{O}_{3}+6 \mathrm{Cl}+\frac{6}{n} \mathrm{H}_{2} \mathrm{O} \\
& 6 \mathrm{Cl} \rightarrow 3 \mathrm{Cl}_{2} \text { and } 6 \mathrm{Cl} \text { or } 3 \mathrm{Cl}_{2}+3 \mathrm{H}_{2} \mathrm{O} \rightarrow 3 \mathrm{HCl}
\end{aligned}
$$

Guillaume et al. [49] reported the influence of chlorination of $\gamma$-alumina (using $\mathrm{HCl}$ gas) on the surface hydroxyl groups through FTIR spectra. They commented that $\gamma$-alumina is characterized by four bands at $3794 \mathrm{~cm}^{-1}, 3775 \mathrm{~cm}^{-1}, 3730 \mathrm{~cm}^{-1}$, and $3686 \mathrm{~cm}^{-1}$, while increasing surface chlorination led in first step to the disappearance of the peaks at highest wavenumbers before causing a decrease in the band at $3730 \mathrm{~cm}^{-1}$; at the highest level of chlorination, the band at $3686 \mathrm{~cm}^{-1}$ is greatly enlarged due to the formation of a new peak at $3661 \mathrm{~cm}^{-1}$. The spectrum obtained with the synthesized mesoporous $\gamma$-alumina shows relatively well-resolved peak at around $3740 \mathrm{~cm}^{-1}$, and almost a disappearance of the peak at around $3801 \mathrm{~cm}^{-1}$ (while the peak at $3775 \mathrm{~cm}^{-1}$ is not detectable). An intermediary level of chlorination is then obtained by the self-chlorination 
of the alumina support during the synthesis. In addition, Guillaume et al. [49] discussed the mechanisms involved in the chlorination of $\gamma$-alumina through sorption on two possible sites of (110) plane: (a) substitution of basic hydroxyl groups on C-layer and (b) heterolytic dissociative adsorption of $\mathrm{HCl}$ with concerted desorption of water on the D-layer. This information was critical for understanding the mechanism involved in $n$-heptane cracking in relation to Lewis and Brønsted acid sites: they suggest that first $n$-heptane is isomerized on the Brønsted acid sites, followed by the cracking of heptane on the strong Lewis acid sites.

In order to gain a better insight into the acid surface properties of the catalyst, the FTIR spectrum was also acquired after pyridine sorption. Indeed, pyridine, which is a Lewis base probe molecule, is very efficient for detecting Lewis and Brønsted acid sites present on alumina $[50,51]$. The interactions between acidic groups at the surface of the catalyst can be readily followed by FTIR spectrometry. The peak near $1457 \mathrm{~cm}^{-1}$ is usually assigned to the sorption of pyridine on Lewis acid sites, while the peaks recorded around 1558 and $1648 \mathrm{~cm}^{-1}$ are usually attributed to Brønsted acid sites [7, 51]. On the other hand, the band at $1510 \mathrm{~cm}^{-1}$ is not specific and can be attributed to interactions with both Lewis and Brønsted acid sites [50], or H-bonded species [43]. The two peaks at $1540 \mathrm{~cm}^{-1}$ and $1620 \mathrm{~cm}^{-1}$ are correlated with pyridine molecules or pyridinium ions [12]. The catalyst is thus bearing both Lewis and Brønsted acid sites opening promising perspectives for the cracking of hydrocarbons.

\section{$\mathrm{NH}_{3}$-TPD measurements}

The surface acidity of catalytic materials is also frequently analyzed using the $\mathrm{NH}_{3}$-TPD method (ammonia temperature-programmed desorption method) [7]. Indeed, ammonia is a small cross-sectional area molecule (i.e., $0.141 \mathrm{~nm}^{2}$ ) that can readily diffuse into porous materials and easily coordinate with acid sites. The $\mathrm{NH}_{3}$-TPD profiles of the freshly prepared and used alumina (and analyzed after calcination at $500{ }^{\circ} \mathrm{C}$ ) are shown in Fig. 3. The catalyst was used for 25 successive runs at different temperatures for cumene conversion and calcined for $6 \mathrm{~h}$ at $500{ }^{\circ} \mathrm{C}$.

The figure shows that mesoporous $\gamma$-alumina holds 3 types of acid groups, corresponding to 3 peaks of different intensities, surface areas, and temperature range for ammonia desorption. Weak, medium, and strong acid sites are identified in the temperature ranges: $120-250{ }^{\circ} \mathrm{C}, 250-430{ }^{\circ} \mathrm{C}$, and from 430 to $500{ }^{\circ} \mathrm{C}$ (and above), respectively [52]. Table 1 reports the results of peak area calculations for the two materials. The first desorption peak corresponding to low-temperature range is directly related to the surface hydroxide groups that represent about $4 \%$ of total acid sites. The second temperature range is associated with medium and strong Brønsted acid sites (accounting for about $5 \%$ of total acid sites on fresh catalyst and about $1 \%$ on used catalyst). Finally, the highest temperature range is assigned to the strongest acid sites (i.e., Lewis acid sites): they are the most represented at the surface of the catalyst accounting for $93-94 \%$ of total acid sites [53]. The values are relatively close for the two materials: the freshly prepared catalyst has lost less than $4 \%$ of strong acid sites after being used and calcined, while the total acidity hardly varied (from 1.71 to $1.69 \mathrm{mmol} \mathrm{g}^{-1}$ ). This is a first indication that the catalyst is remarkably stable in terms of surface acidity, probably due to the strong binding of chlorine on the support during catalyst synthesis. These conclusions are consistent with the discussion of FTIR spectrum for mesoporous $\gamma$-alumina loaded with pyridine (see above) in terms of presence of strong Lewis and Brønsted acid sites $\left(1.713 \mathrm{mmol} \mathrm{g}^{-1}\right)$ and stability (negligible variation in the percentage of strong acid sites). These values are much higher than the levels reported by Sazegar et al. [54]: while listing the concentrations of Brønsted and

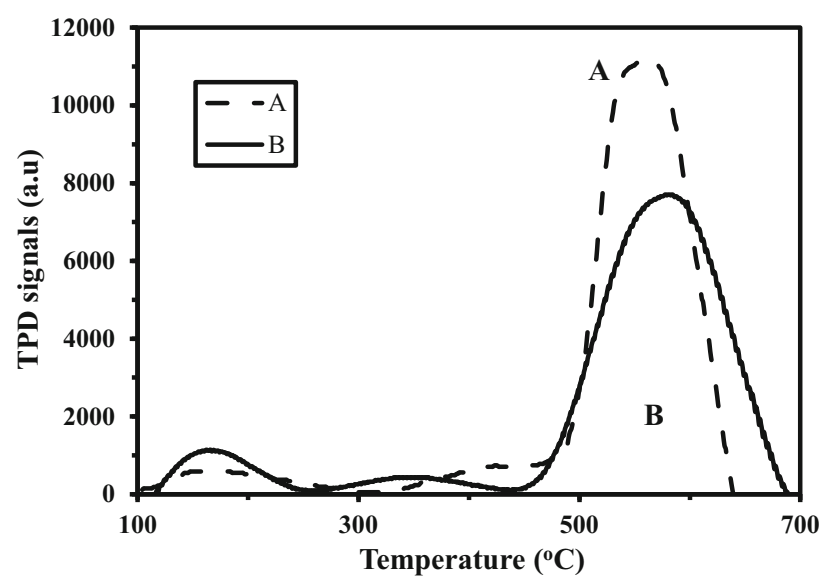

Figure $3 \mathrm{NH}_{3}$-TPD profiles of freshly prepared mesoporous $\gamma$ alumina (A, dashed line) and after cumene dealkylation and calcination at $500{ }^{\circ} \mathrm{C}(\mathrm{B}$, continuous line). 
Table 1 Analysis of surface acid properties (total acidity, weak, medium, and strong acidities) for synthesized $\gamma$-alumina, before and after catalytic use (measurements through the $\mathrm{NH}_{3}$-TPD method)

\begin{tabular}{lllll}
\hline Sample & $\begin{array}{l}\text { Total acidity } \\
\left(\mathrm{mmol} \mathrm{g}^{-1}\right)\end{array}$ & $\begin{array}{l}\text { Weak acidity } \\
\left(\mathrm{mmol} \mathrm{g}^{-1}\right)\end{array}$ & $\begin{array}{l}\text { Medium acidity } \\
\left(\mathrm{mmol} \mathrm{g}^{-1}\right)\end{array}$ & $\begin{array}{l}\text { Strong acidity } \\
\left(\mathrm{mmol} \mathrm{g}^{-1}\right)\end{array}$ \\
\hline $\begin{array}{l}\text { Mesoporous } \gamma \text {-alumina } \\
\begin{array}{l}\text { Mesoporous } \gamma \text {-alumina after } \\
\text { use }\end{array}\end{array}$ & 1.85 & 0.06 & 0.08 & 1.713 \\
\end{tabular}

Lewis acid sites for a series of acid catalysts, they mentioned values ranging below $170 \mu \mathrm{mol} \mathrm{g}^{-1}$ and below $189 \mu \mathrm{mol} \mathrm{g}^{-1}$, respectively. With aluminosilicate catalyst ZSM-5, Barakov et al. reported values close to $0.149 \mu \mathrm{mol} \mathrm{g}^{-1}$ for both Lewis and Brønsted acid sites. Comparable levels to SAGMA material were obtained in the case of Al-silica-pillared clay material (i.e., $1.78 \mathrm{mmol} \mathrm{g}^{-1}$ ) [55] and nanosizedZSM-5/SBA-15 composites (i.e., $1.28 \mathrm{mmol} \mathrm{g}^{-1}$ ) [32]. The remarkable characteristics of SAGMA catalyst are confirmed by Table 2 that reports some data obtained in the literature for conventional catalytic materials used for cumene conversion.

\section{SEM analysis (surface morphology)}

Figure AM2 (see Additional Material Section) shows the SEM micrographs of mesoporous $\gamma$-alumina: the particles are relatively homogeneous in shape and size: rounded microparticles with size ranging between 10 and $40 \mu \mathrm{m}$ are observed. The surface appears irregular with holes and vacancies/valleys offering high external surfaces. The small size of the mesoporous $\gamma$-alumina limits the possible contribution of resistance to intraparticle diffusion for sorption/catalytic applications; however, this size is large enough to make possible the use of this support in conventional processes without requiring specific or sophisticated phase separation technologies. Indeed, the granular size of the product is close to $0.25 \mathrm{~mm}$ (60 mesh); this is small enough for developing an appreciable external surface area (in addition to the specific surface area of mesoporous material) but large enough to make relatively easier the selfgravimetric separation of the particles from the reactive media (during the synthesis for example).

It is usually recommended to use micron-size catalyst particles to prevent diffusion hindrance and improve catalytic performance. Indeed, the textural properties directly affect mass transfer properties and reactivity of the support. However, on a practical point of view while using tubular/column reactors using small particles (around $30 \mu \mathrm{m}$ ) may cause nonnegligible head loss of pressure and even blockage that prevent using these systems for continuous stream flows. It is thus generally necessary to process to the shaping of the catalyst microparticles when transferring the process from laboratory scale to pilot scale and at industrial scale. The extrusion of the catalyst under controlled shapes and the agglomeration of the micro-particles (pelletization) are common processes used for elaborating industrial catalysts. The present manufacturing process for production of SAGMA reveals a good compromise for preventing flow dynamic constraints with maintaining relatively high catalytic performance.

\section{Surface area and pore size distribution}

The textural characteristics of synthesized mesoporous $\gamma$-alumina catalyst were studied using $\mathrm{N}_{2}$ physisorption experiments at $-196^{\circ} \mathrm{C}$. The $\mathrm{N}_{2}$ adsorption-desorption isotherm and the corresponding pore size distribution derived from the $\mathrm{BJH}$ method using the desorption branch of the isotherm are shown in Fig. 4. According to the figure, the prepared alumina exhibited type IV isotherm with a type-3 hysteresis loop between $P / P_{\mathrm{o}}=0.5$ and 0.95 ; this value is consistent with the IUPAC classification of mesoporous materials. The pore size distribution curve of the synthesized alumina showed a monomodal class with a mean pore diameter of $7.8 \mathrm{~nm}$. Moreover, the mesoporous $\gamma$-alumina had a high surface area of $230 \mathrm{~m}^{2} \mathrm{~g}^{-1}$ and large pore volume of $0.46 \mathrm{~cm}^{3} \mathrm{~g}^{-1}$. Bonelli et al. [56] investigated the impact of prolonged magnetic stirring on the textural properties of nanometric transition alumina (containing both $\delta$ - and $\gamma$-alumina) and found relatively low specific surface areas (around $35 \mathrm{~m}^{2} \mathrm{~g}^{-1}$ ). Wang et al. [57] reported values in the range $300-400 \mathrm{~m}^{2} \mathrm{~g}^{-1}$ for 
Table 2 Comparison of characteristics of catalysts used for cumene conversion and relevant catalytic properties

\begin{tabular}{|c|c|c|c|c|c|c|}
\hline \multirow[t]{2}{*}{ Catalyst } & \multirow{2}{*}{$\begin{array}{l}\text { Total acidity } \\
\left(\mathrm{mmol} \mathrm{g}^{-1}\right)\end{array}$} & \multirow{2}{*}{$\begin{array}{l}\text { Total } \\
\text { conversion } \\
(\%)\end{array}$} & \multicolumn{2}{|l|}{ Selectivity } & \multirow{2}{*}{$\begin{array}{l}\text { Experimental } \\
\text { conditions }\end{array}$} & \multirow[t]{2}{*}{ References } \\
\hline & & & $\begin{array}{l}\text { Dealkylation } \\
(\%)\end{array}$ & $\begin{array}{l}\text { Dehydrogenation } \\
(\%)\end{array}$ & & \\
\hline SAGMA catalyst & $1.85^{\mathrm{a}}$ & 87 & $\approx 100$ & nil & $\begin{array}{l}\text { T } 300{ }^{\circ} \mathrm{C}- \\
\text { LHSV } 4 \mathrm{~h}^{-1} \\
\mathrm{~N}_{2} \text { gas-P } 1 \text { atm }\end{array}$ & This work \\
\hline $\begin{array}{l}\text { Al-grafted mesostructured silica } \\
\text { nanoparticles }\end{array}$ & $0.285^{\mathrm{b}}$ & 58 & 63 & 37 & $\begin{array}{l}\text { T } 300{ }^{\circ} \mathrm{C}- \\
\text { LHSV } 1.5 \mathrm{~h}^{-1} \\
\mathrm{H}_{2} \text { gas-P } 1 \mathrm{~atm}\end{array}$ & {$[54]$} \\
\hline $\mathrm{Nb}_{2} \mathrm{O}_{5}-\mathrm{WO}_{3}$ & n.d. & 35 & n.d. & n.d. & $\begin{array}{c}\text { T } 300{ }^{\circ} \mathrm{C}-\text { Pulse, } \\
1 \mu \mathrm{L} / 0.5 \mathrm{~g} \\
\mathrm{H}_{2} \text { gas-P } 1 \mathrm{~atm}\end{array}$ & {$[6]$} \\
\hline $\mathrm{Al}_{2} \mathrm{O}_{3}-\mathrm{F}^{-}$ & n.d. & 80 & 95 & 5 & $\begin{array}{l}\mathrm{T} 400{ }^{\circ} \mathrm{C}- \\
\text { LHSV } 1.5 \mathrm{~h}^{-1} \\
\mathrm{H}_{2} \text { gas- }-\mathrm{P} 1 \mathrm{~atm}\end{array}$ & {$[43]$} \\
\hline Mordenite $(\mathrm{Si} / \mathrm{Al}=48)$ & $0.265^{\mathrm{a}}$ & 52 & 40 & 60 & $\begin{array}{l}\text { T } 300{ }^{\circ} \mathrm{C}- \\
\text { LHSV } 2.3 \mathrm{~h}^{-1} \\
\mathrm{~N}_{2} \text { gas- } \mathrm{P} \\
19.7 \mathrm{~atm}\end{array}$ & {$[73]$} \\
\hline $\begin{array}{l}\text { Aluminated mesoporous-silica- } \\
\text { pillared montmorillonite }\end{array}$ & $1.78^{\mathrm{a}}$ & 65 & n.d. & n.d. & $\begin{array}{l}\text { T } 300{ }^{\circ} \mathrm{C}- \\
\text { LHSV } 2.5 \mathrm{~h}^{-1} \\
\mathrm{~N}_{2} \text { gas- } \mathrm{P} \\
19.7 \mathrm{~atm}\end{array}$ & {$[55]$} \\
\hline $10 \% \mathrm{P}^{-\mathrm{TiO}_{2}}$ & $0.38^{\mathrm{b}}$ & 85.5 & 89 & 11 & $\begin{array}{l}\text { T } 500{ }^{\circ} \mathrm{C}-\text { Pulse, } \\
1 \mu \mathrm{L} / \mathrm{g} \\
\text { Ne gas-P } 1 \mathrm{~atm}\end{array}$ & {$[74]$} \\
\hline
\end{tabular}

n.d. not documented

${ }^{a}$ Measured by TPD

${ }^{\mathrm{b}}$ Measured by pyridine-adsorbed FTIR

Figure $4 \quad \mathrm{~N}_{2}$ adsorptiondesorption isotherm and $\mathrm{BJH}$ mesoporous size distribution of the pores for mesoporous $\gamma$ alumina.

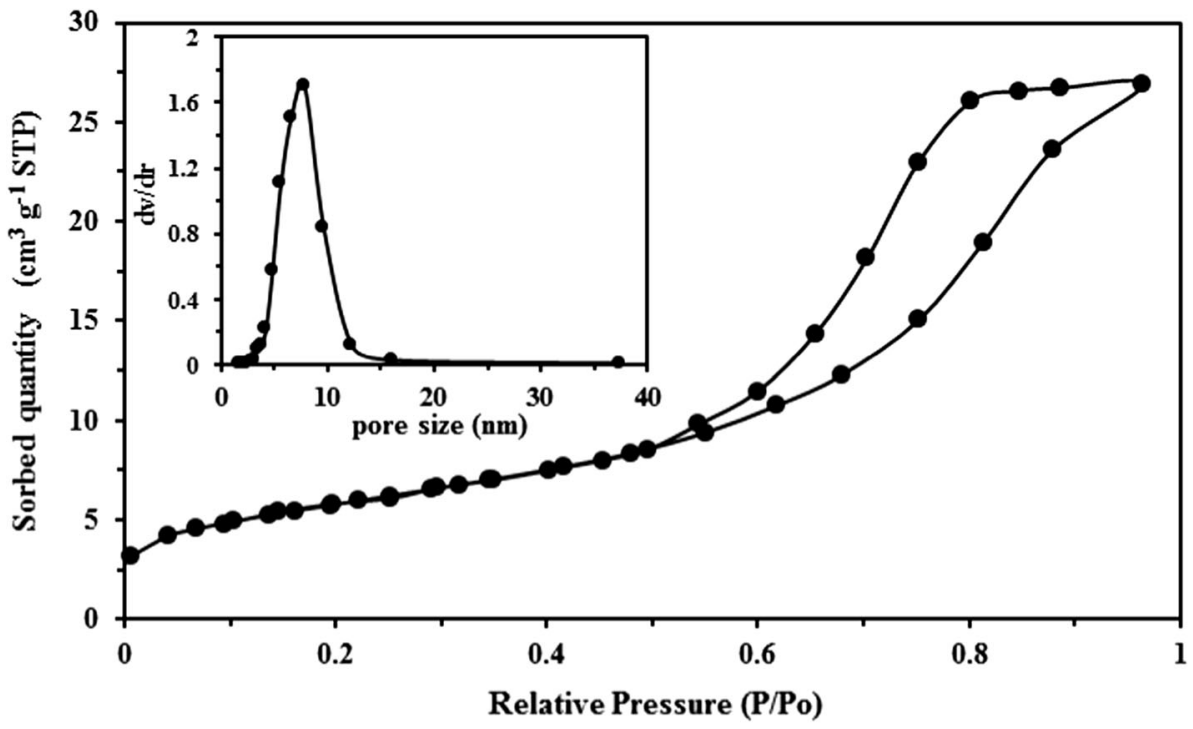


the specific surface area of alumina synthesized in the presence of sucrose (with pore size close to $3.7 \mathrm{~nm}$ ). Dabbagh et al. [58] described the synthesis of alumina nanorods with specific surface areas strongly varying with the temperature used: most of them being in the range $200-300 \mathrm{~m}^{2} \mathrm{~g}^{-1}$ with pore sizes in the range 4-14 nm. Pai et al. [59] used a sol-gel process for the synthesis of $\gamma$-alumina and obtained specific surface area between 220 and $250 \mathrm{~m}^{2} \mathrm{~g}^{-1}$ and pore sizes in the range 4-14 $\mathrm{nm}$. Mrabet et al. [60] described a simple method for the manufacturing of nanosized $\gamma$ alumina using oleylamine as the capping agent that prevents the agglomeration (a role close to that played by wax in the present work), and they obtained specific surface areas close to $350 \mathrm{~m}^{2} \mathrm{~g}^{-1}$ with pore sizes ranging between 3.5 and $50 \mathrm{~nm}$, depending on the amount of nitric acid used. Sachse et al. [61] reported the facile synthesis of $\gamma$-alumina having narrow pore size close to $6 \mathrm{~nm}$ with a specific surface area close to $400 \mathrm{~m}^{2} \mathrm{~g}^{-1}$. Mei et al. [62] reported the increase in specific surface area (and more generally the improvement in textural properties) by incorporation of polyethylene glycol in the sol-gel process of alumina synthesis: the appropriate selection of both length of PEG and added amount allows tuning the pore size of the catalytic support (used for formaldehyde oxidation). The process used in this study produces a mesoporous support with textural properties consistent with the literature data on $\gamma$-alumina. Such high specific surface areas are favorable parameters for sorption and catalytic usage.

\section{HRTEM and EDX analyses}

The characterization of morphology and composition of catalyst was completed by HRTEM (Fig. 5) and EDX (Fig. 6) analyses. The dehydrated $\mathrm{AlCl}_{3}$-nanorods (Fig. 5a) show very uniform dispersed objects with similar size (in the range $50-100 \mathrm{~nm}$ for the length and about 5-10 $\mathrm{nm}$ for the diameter) and shape (rods). Using petroleum wax as a capping agent during the synthesis of the material contributes to limiting the self-aggregation of the microparticles. Similar structures were obtained by Mrabet et al. [60] while using oleylamine as the capping agent: the morphology (spherical vs. rod shapes) of obtained catalysts depended on the amount of nitric acid used for the synthesis in Teflon autoclave (using aluminum isopropoxide as precursor). Dabbagh et al. [58] reports the formation of nanorods of alumina in the presence of alanine, which stabilizes the transition alumina structure during the synthesis. In addition, the presence of alanine appears to change the mobility of surface groups: surface hydroxyl groups are converted into ester moieties that leave more readily the surface during the conversion of aluminum isopropoxide to $\gamma-, \delta$ - or $\theta$-alumina; this allows reducing the temperature for aluminum isopropoxide dehydration. The present process uses much simple aluminum precursor (aluminum chloride, $\mathrm{AlCl}_{3}$ ) and petroleum wax as capping agent under relatively simple and poorly aggressive conditions (simple reactor) and allows obtaining microsize objects with nanosize crystals of similar shape (nanorods) compared to alternative processes. After the oxidation of the $\mathrm{AlCl}_{3}$-nanorods in the second step of the synthesis, the catalyst forms dendrimer planar structures (Fig. 5b). The flower- or leaflike objects are constituted of dendritic branches of 3-4 $\mu \mathrm{m}$ lengths offering high contact surfaces that are of great interest for sorption and catalytic applications. This shape is typically induced by strict control of crystal growing conditions; for example, dendritic leaf structures were observed in the growth of gold nanostructures by reaction of chloroauric acid, dodecyltrimethylammonium bromide, and $\beta$-cyclodextrin [63]. The formation of a supramolecular complex between the cyclodextrin and the surfactant is necessary for forming gold dendritic leaves or flowers; the final shape is controlled by the molar ratio between these capping supramolecular agents. One could assume that petroleum wax plays a kind of control in the final arrangement of alumina structure: the vigorous stirring of petroleum wax with aluminum chloride forms a water-in-oil emulsion that enhances homogeneous dehydration and prevents coarse agglomeration of nanorods in first step, before contributing to the controlled growth of dendritic structure. The presence of wax in the synthesis procedure may have different effects. The capping effect of hydrophobic agents has already been documented. For example, in the case of oleylamine, the presence of this agent allows producing nanosized $\gamma$ alumina with controlled shape (spherical or rod shape); Mrabet et al. [60] attribute to oleylamine the effect of a capping agent that prevents the aggregation of particles. However, it seems that wax can also play a role in the stabilization of the fine droplets of $\mathrm{AlCl}_{3}$ during the vigorous stirring (and rising temperature) step of the process. Actually, the 
Figure 5 HRTEM profiles of TEM microphotographs of $\mathrm{AlCl}_{3}$-nanorods (a) and mesoporous $\gamma$-alumina (b).
Figure 6 EDX analysis of freshly prepared mesoporous $\gamma$-alumina (a), and (b) after cumene dealkylation and calcination at $500{ }^{\circ} \mathrm{C}$.
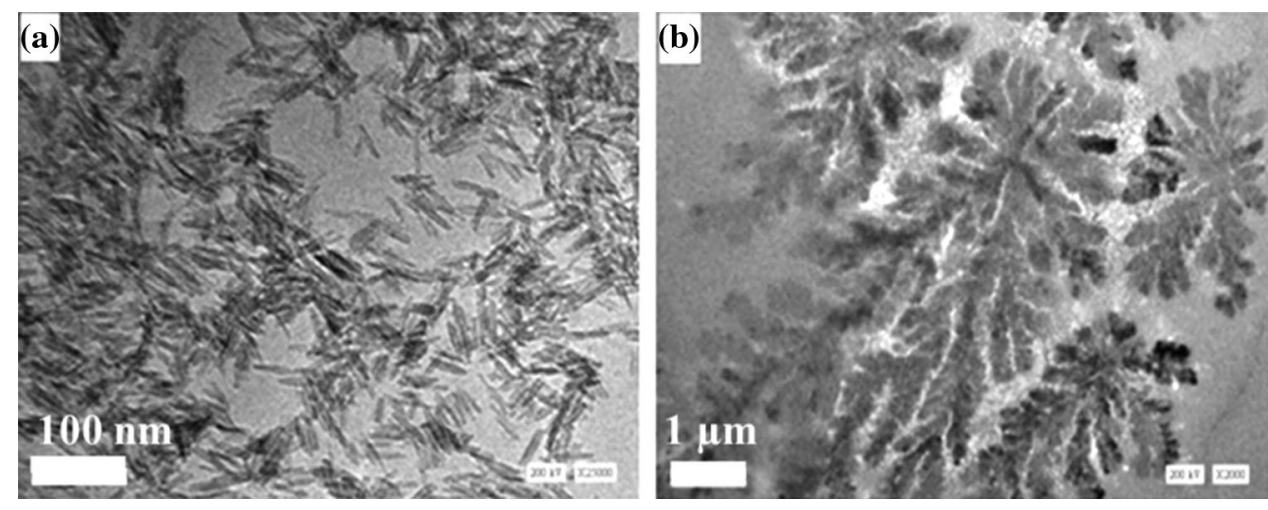

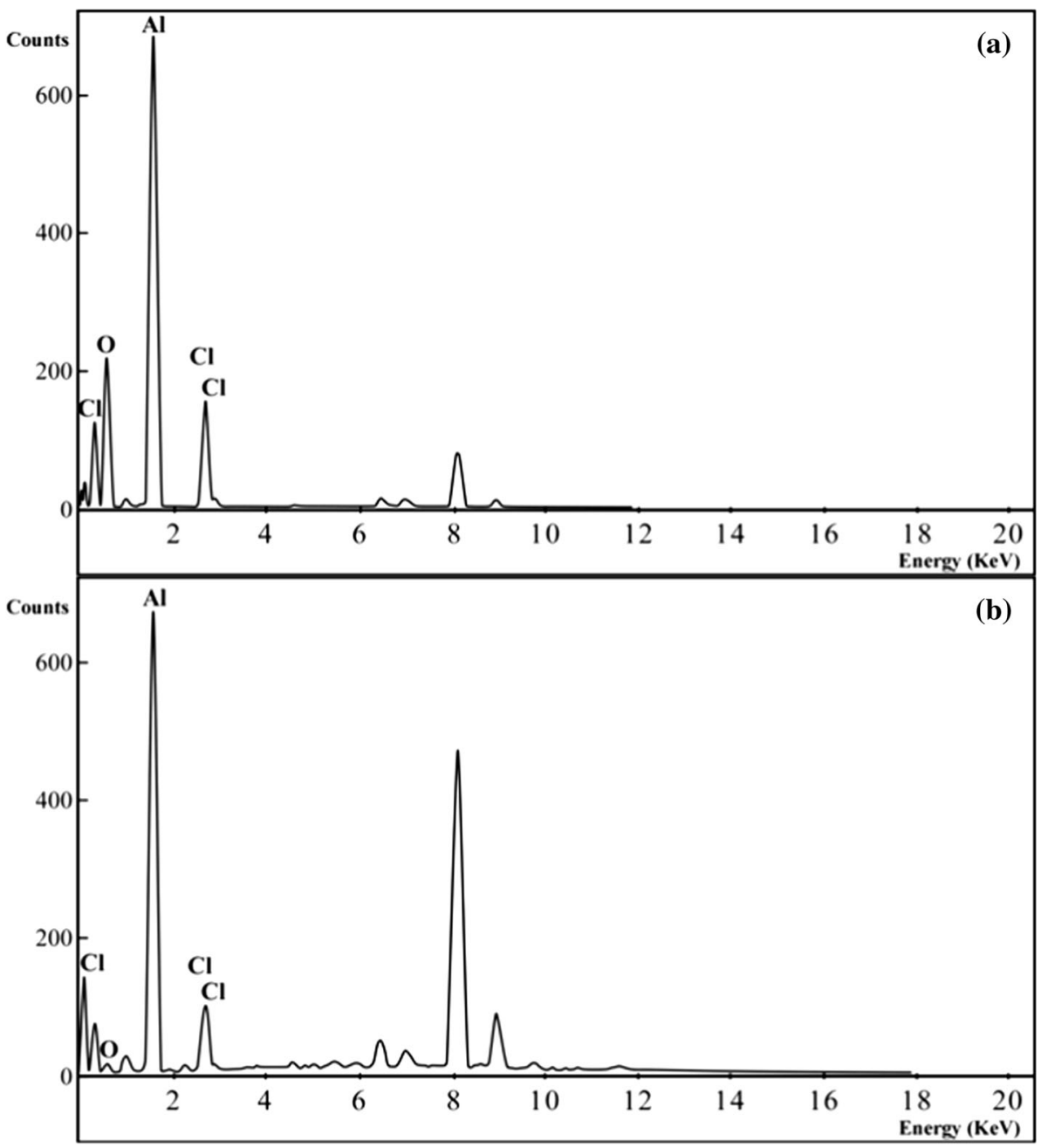

observation of the emulsion formed under these drastic conditions demonstrates the presence of a colloidal suspension that remains stable over $24 \mathrm{~h}$; this is directly connected to a mechanism of water-inoil emulsion formation [64, 65]. This contributes to explain the synthesis of well-crystalline morphologies and to facilitate the dehydration step of the droplets with formation of $\mathrm{AlCl}_{3}$-nanorods. In the second step of the process (corresponding to oxidation in the presence of air in the closed system), the wax facilitates the dispersion of the nanorods and prevents their agglomeration. An additional benefit could be associated with the evolution and release of chloride/chlorine during the oxidation step, which 
make them available for re-incorporation and graphitization at the surface of synthesized chlorinated $\gamma$-alumina. SEM-EDX analysis showed that the $\mathrm{Cl}$ content at the surface of the catalyst is close to $5.35 \pm 0.49 \%(\mathrm{w} / \mathrm{w})$. This may explain the high acidity of SAGMA catalyst.

The chemical composition of the catalyst before and after cumene conversion (and final calcination step at $500{ }^{\circ} \mathrm{C}$ ) is illustrated by Fig. 6 (EDX analysis of the surface of materials). The EDX spectra clearly show the $\mathrm{Al}$ and $\mathrm{O}$ elements constitutive of the core material but also the presence at the surface of the solid of $\mathrm{Cl}$ element: this demonstrates the efficient self-chlorination of mesoporous $\gamma$-alumina following selected synthesis route and that the support is stable in terms of acidity and chloride content even after 25 runs and calcination at $500{ }^{\circ} \mathrm{C}$. The synthesis route is not only simple, economically competitive but also remarkably stable (consistently with other previous characterizations).

\section{Thermal analyses}

The thermogravimetric analyses (TGA) and differential scanning calorimetry (DSC) profiles of the prepared alumina and conventional aluminum hydroxide are shown in Fig. 7. The first weight loss of aluminum hydroxide (below $200{ }^{\circ} \mathrm{C}$ ) corresponds to the loss of absorbed water (counting for about 20\%); above $200{ }^{\circ} \mathrm{C}$ and up to $350{ }^{\circ} \mathrm{C}$, another loss that represents about $35 \%$ corresponds to the theoretical weight loss for the conversion of $\mathrm{Al}(\mathrm{OH})_{3}$ into $\mathrm{Al}_{2} \mathrm{O}_{3}$ (which includes dehydroxylation and phase transition, as shown in Fig. 7a, TGA panel). Above $350{ }^{\circ} \mathrm{C}$ and up to $500{ }^{\circ} \mathrm{C}$, another $5 \%$ of initial weight is lost (probably associated with the crystallization of alumina [58]). The characteristic endothermic peaks are observed at around $65-75{ }^{\circ} \mathrm{C}$ and $260{ }^{\circ} \mathrm{C}$ for the release of absorbed water and the dehydration of aluminum hydroxide and phase conversion, respectively (Fig. 7b, DSC panel). In the case of mesoporous $\gamma$-alumina, the initial weight loss (below $200{ }^{\circ} \mathrm{C}$ ) represents about $10 \%$; the endothermic peak is identified at $55^{\circ} \mathrm{C}$. Above $200{ }^{\circ} \mathrm{C}$, a progressive and slight weight loss is detected but represents only $10 \%$ of total mass. The second endothermic peak does not appear in this case. The TGA profiles show that the prepared mesoporous $\gamma$-alumina had a lower weight loss (i.e., about 20\%) compared to aluminum hydroxide (i.e., 54\%: water loss between 43 and
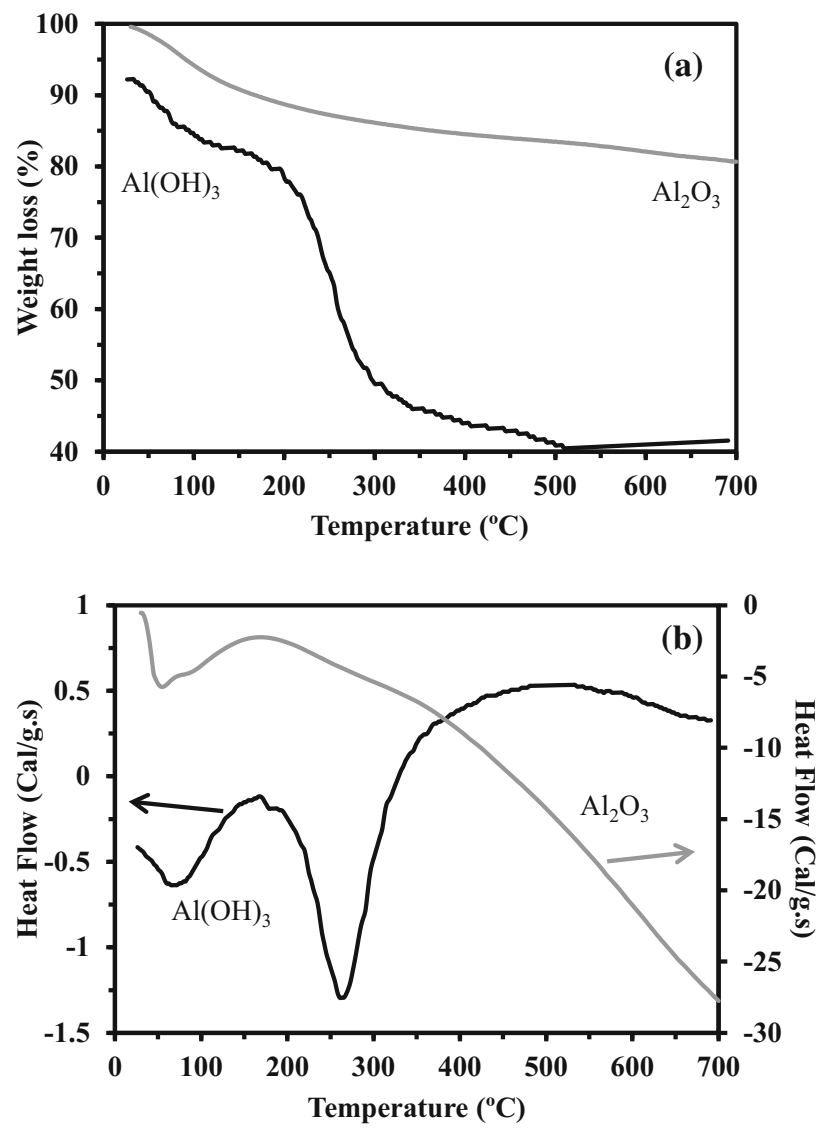

Figure 7 TGA (a) and DSC (b) profiles for mesoporous $\gamma$ alumina $\left(\mathrm{Al}_{2} \mathrm{O}_{3}\right)$ and conventional aluminum hydroxide $\left(\mathrm{Al}(\mathrm{OH})_{3}\right.$, as a reference or standard for the determination of endothermic/ exothermic peaks).

$185^{\circ} \mathrm{C}$, followed by dehydroxylation at $185-360^{\circ} \mathrm{C}$ ). Total weight loss does not exceed $20 \%$ at $700{ }^{\circ} \mathrm{C}$ compared to aluminum hydroxide that lost about $60 \%$ of its initial weight. This is less than the weight losses observed in the case of mesoporous alumina nanorods produced in the presence of phenolformaldehyde templates [66]. These results prove the stability of synthesized $\gamma$-alumina although the oxidation of $\mathrm{AlCl}_{3}$ to alumina was processed at relatively low temperature (i.e., $300{ }^{\circ} \mathrm{C}$ ). The strong DSC peak observed at $260{ }^{\circ} \mathrm{C}$ for aluminum hydroxide corresponds to the transition for the formation of alumina [67]. In the case of $\gamma$-alumina, apart from the heat release observed around $55{ }^{\circ} \mathrm{C}$ that corresponds to the release of absorbed water, it is not possible detecting a strong peak; the heat release continuously decreases with absolute values much higher than for aluminum hydroxide transitions $\left(0\right.$ to $-30 \mathrm{~W} \mathrm{~g}^{-1}$ for mesoporous $\gamma$-alumina vs. +0.5 to $-1.5 \mathrm{~W} \mathrm{~g}^{-1}$ for 
aluminum hydroxide). The thermal profile also confirms the stability of the bonded chloride on synthesized mesoporous $\gamma$-alumina; indeed, it was not possible detecting any peak assigned to the release of chloride/chlorine even at high temperatures $\left(500-700{ }^{\circ} \mathrm{C}\right)$, consistently with TPD measurements.

\section{Study of catalytic activity}

The catalytic efficiency of mesoporous $\gamma$-alumina was tested using cumene conversion. The conversion was processed under $\mathrm{N}_{2}$ atmosphere at different temperatures (in the range $150-350{ }^{\circ} \mathrm{C}$ ) and varying the flow rate of the substrate in the catalytic fixed-bed column (LHSV 2 and $4 \mathrm{~h}^{-1}$ ). Cumene is a probe molecule that is frequently used for investigating the effect of surface acidity of zeolite [5], mesoporous [54], and other catalytic materials [68]. Its disproportionation may occur through two main pathways: (a) the dealkylation route and (b) the dehydrogenation route. The research background in this field demonstrated that the dealkylation pathway is enhanced by strong Lewis acid sites (involving the cracking of cumene into benzene and ethyl benzene), while the dehydrogenation pathway occurs under the effect of weak/moderate Brønsted acid sites (giving rise to $\alpha$ methylstyrene as a main product) as illustrated in Fig. 8 [43]. Corma et al. [69] reported that the interaction of cumene with a Brønsted acid site (on silicaalumina surfaces) proceeded through the attack to the para position (driven by the protonation channels for long-distance interactions), while for distances between 2 and $3 \AA$ the interaction is delocalized along the benzene ring.

Figure 9 shows the effect of temperature on cumene conversion by SAGMA catalyst, while the distribution of products and percentages of conversion are given in Table 3. The conversion efficiency increases with temperature till a maximum which depends on the flow rate of cumene fed in the column: in the range $250-300{ }^{\circ} \mathrm{C}$ at low flow rate and a little higher (i.e., at $300{ }^{\circ} \mathrm{C}$ ) for the higher LHSV (i.e., $4 \mathrm{~h}^{-1}$ ) (Fig. 9). Reducing the contact time in the reactor requires slightly increasing the temperature for achieving the same level of conversion (close to 85-87\%). The comparison of the composition of the products of the reaction clearly demonstrates that methylstyrene is not produced during the reaction: the main product is represented by benzene though some side products [i.e., ethyl benzene, toluene, and light gases $\left.\left(C_{1}-C_{5}\right)\right]$ are also produced depending on experimental conditions (temperature and flow rate). At low LHSV (i.e., $2 \mathrm{~h}^{-1}$ ), the reaction is strongly oriented toward the synthesis of benzene and side products (light gases and ethyl benzene) represent a marginal fraction of the reactive media, at least at low temperature. Increasing the temperature to $350{ }^{\circ} \mathrm{C}$ affects both the conversion efficiency (decreased to less than 55\%) and the synthesis of side products (which represent about 25\% of the products). Increasing the flow rate (i.e., LHSV: $4 \mathrm{~h}^{-1}$ ) shows similar trends but with a higher relative synthesis of side products (which count for up to $70 \%$ at $250{ }^{\circ} \mathrm{C}$ and $52 \%$ at $350{ }^{\circ} \mathrm{C}$ ). Figure 10 shows the benzene

Figure 8 General scheme for cumene conversion (possible routes).

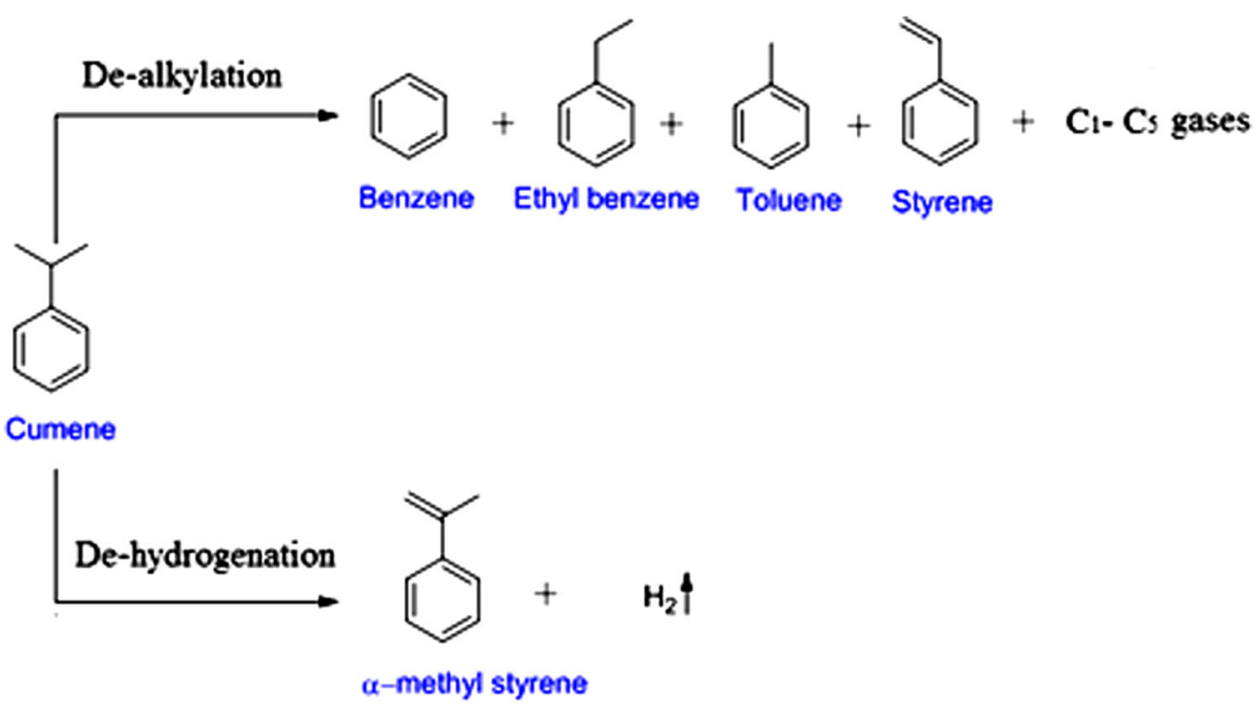




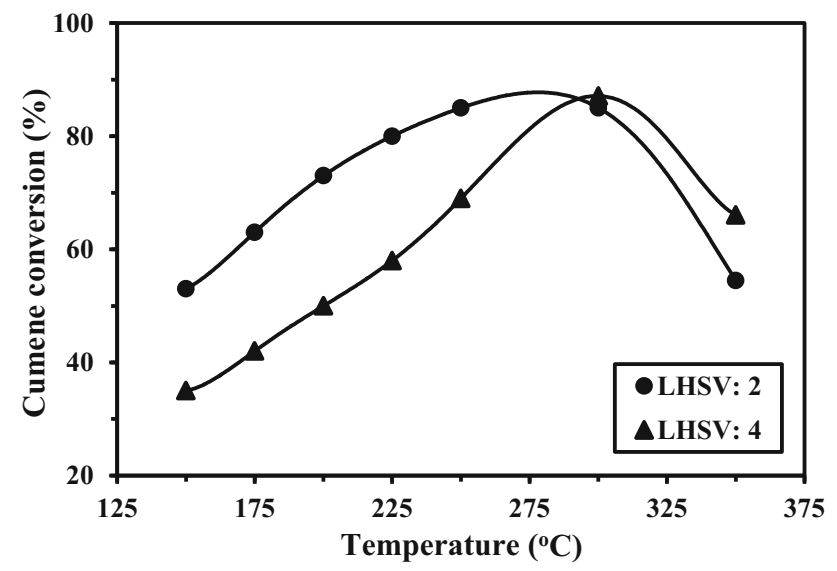

Figure 9 Effect of reaction temperature and LHSV on cumene conversion efficiency (\%).

selectivity (calculated as the percentage of benzene produced against total products of the reaction). At low LHSV, the selectivity for benzene gradually increases with temperature but sharply decreases above $300{ }^{\circ} \mathrm{C}$. However, at high HLSV (i.e., $4 \mathrm{~h}^{-1}$ ), it is not possible defining a clear trend in terms of benzene selectivity. The short contact time in the reactor may cause some parallel and uncontrolled side reactions; the reasons are not clearly elucidated at this stage. It is noteworthy that the freshly prepared catalyst gave a much continuous variation of the selectivity: the selectivity for benzene synthesis progressively increased between 150 and $250{ }^{\circ} \mathrm{C}$, and then sharply increased to more than $90 \%$ at $300{ }^{\circ} \mathrm{C}$ before sharply decreasing at $350{ }^{\circ} \mathrm{C}$. This means that for both freshly prepared and aged catalyst at high LVMH (i.e., $4 \mathrm{~h}^{-1}$, meaning low contact time) the

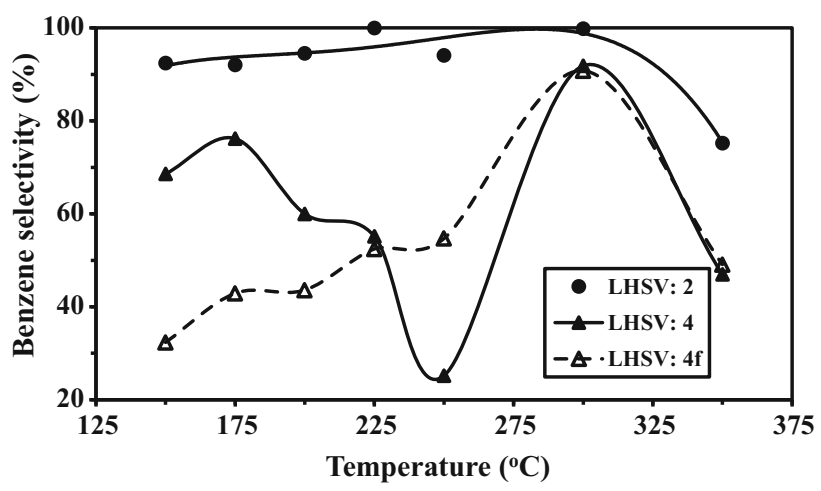

Figure 10 Effect of LHSV and temperature on benzene synthesis selectivity (benzene percentage in the products of the reaction; LHSV: $4 \mathrm{f}$ corresponds to the repetition tests with freshly prepared catalyst).

optimum temperature for benzene selectivity remains close to $300{ }^{\circ} \mathrm{C}$.

The high efficiency of SAGMA catalyst is directly connected to the strong acidity of material surface that bears many Lewis and Brønsted acid sites (associated with self-chlorination of the surface, as shown by TPD, FTIR characterizations), and the mesoporous structure (both the pore size and the high specific surface enhance the accessibility of substrate and products to active surfaces, as shown by TEM, SEM, and BET analyses). The pore size of synthesized mesoporous $\gamma$-alumina has been evaluated close to $7.8 \mathrm{~nm}$ (from textural analysis, see above). This is consistent with the average dimensions (equivalent molecular diameters) of cumene and other products implicated in the reactions (i.e., between 4.3 and $7.25 \AA$ ):

Table 3 Cross effects of LHSV and reaction temperature on the conversion efficiency in cumene dealkylation using synthesized $\gamma$-alumina and the distribution of reaction products

\begin{tabular}{|c|c|c|c|c|c|c|c|c|c|c|c|c|c|c|}
\hline \multirow[t]{2}{*}{ Temperature $\left({ }^{\circ} \mathrm{C}\right)$} & \multicolumn{7}{|c|}{$\mathrm{LHSV}=2 \mathrm{~h}^{-1}$} & \multicolumn{7}{|c|}{$\mathrm{LHSV}=4 \mathrm{~h}^{-1}$} \\
\hline & 150 & 175 & 200 & 225 & 250 & 300 & 350 & 150 & 175 & 200 & 225 & 250 & 300 & 350 \\
\hline Cumene conversion $(\%)$-average & 53.0 & 63.0 & 73.1 & 80.0 & 85.0 & 85.1 & 54.6 & 35.0 & 42.0 & 50.0 & 58.1 & 69.1 & 87.1 & 66.1 \\
\hline Standard deviation & 0.1 & 0.4 & 0.5 & 0.1 & 0.1 & 0.4 & 0.1 & 0.1 & 0.2 & 0.1 & 0.1 & 0.1 & 0.1 & 0.1 \\
\hline $\mathrm{C}_{1}-\mathrm{C}_{6}$ Aliphatic compounds (gas) & 2 & 3 & 1 & 0 & 1 & 0.1 & 4.7 & 4 & 4 & 6 & 9 & 12.4 & 4 & 15.7 \\
\hline Benzene & 49 & 58 & 69 & 80 & 80 & 84.85 & 41 & 24 & 32 & 30 & 32 & 17.4 & 80 & 31 \\
\hline Toluene & 0 & 0 & 0 & 0 & 0 & 0 & 1.5 & 0 & 0 & 0 & 0 & 0 & 0 & 4 \\
\hline Ethyl benzene & 2 & 2 & 3 & 0 & 4 & 0.05 & 7.3 & 7 & 6 & 14 & 17 & 39.3 & 3.1 & 15.3 \\
\hline Benzene selectivity & 92.4 & 92.1 & 94.5 & 100.0 & 94.1 & 99.8 & 75.2 & 68.6 & 76.2 & 60.0 & 55.2 & 25.2 & 91.8 & 47.0 \\
\hline
\end{tabular}

Triplicated experiments 


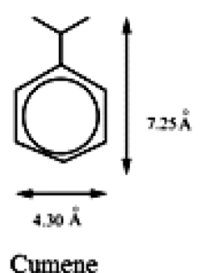

Cumene

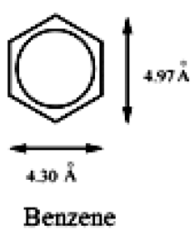

Benzene

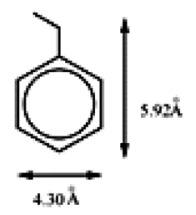

Ethylbenzene

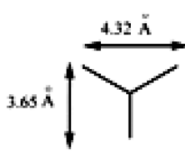

Propyl radical
As a consequence, the steric parameters are favorable to efficient conversion of cumene and release of the products of the reaction. This is even facilitated by flushing $\mathrm{N}_{2}$ gas (equivalent diameter $3.64 \AA$ ) as the carrier gas for efficient transfer of molecules through the porosity of the catalyst. The efficiency of the catalyst is not only controlled by the steric factor (lattice spacing) but also the crystal symmetry of the reactant and products [70].

It is noteworthy that the high conversion efficiency is obtained at relatively low temperature: at LHSV $2 \mathrm{~h}^{-1}$, a temperature as low as $200{ }^{\circ} \mathrm{C}$ allows reaching $80 \%$ conversion of cumene. This may be explained by two possible mechanisms: (a) the dealkylation of cumene to benzene and propene followed by further cracking of propene to form carbon and hydrogen, or (b) the dealkylation of cumene to benzene followed by a complementary reaction of propene in the catalyst mesopores to form benzene. The complete conversion of cumene into benzene and propyne (plus hydrogen gas) would theoretically produce a mixture containing (in the gaseous phase) 66\% of benzene and $34 \%$ of propyne (not considering, in the mass balance, the production of coke-based materials and hydrogen, actually about $2 \%$ of products issued from complete conversion, which is not detectable by GC). Coke formation is negligible (see below) at optimum temperature (i.e., $300{ }^{\circ} \mathrm{C}$ ); the mass balance on $\mathrm{C}$ element is globally respected and served to determine the selectivity of benzene production (Table 3). The analysis of the compounds in the reactor at the end of the reaction, using GC, showed that benzene production reached $80 \%$ at $225{ }^{\circ} \mathrm{C}$. This means much more than expected GC level (i.e., 66\%) and much more than the maximum production of benzene if the conversion runs on the bases of stoichiometric reaction. The absence of other detectable gaseous sub-products (among the byproducts potentially synthesized) means that the reaction is selective and complete. The GC analysis also demonstrates that toluene, styrene, and methylstyrene are not present in the products of the reaction: the reaction is selectively oriented to the formation of benzene and ethylbenzene (at much lower fraction).

Though the strict mass balance on $\mathrm{C}$ was not systematically determined, for selected experiment the quantification of coke formation at the surface of the catalyst (measured by SEM-EDX analysis) represents a maximum of $1.47 \%$. Assuming this amount to be homogeneously distributed in the whole mass of the catalyst, this would represent $14.7 \mathrm{mg}$ of C (or less than $1.23 \mathrm{~mol}$ ). Compared to the amount of cumene injected into the reactor during this experiment, coke formation represents about $3.6 \%$ of total carbon. This is negligible, and the results summarized in Table 3 confirm the selectivity of cumene conversion.

The EDX analysis performed on the SAGMA catalyst after being reacted with cumene at different temperatures shows a marginal deposition of $\mathrm{C}$ element at the surface of the material: undetectable for reaction temperature between 150 and $250{ }^{\circ} \mathrm{C}$, and less than $1.5 \%$, even at $\mathrm{T} 350{ }^{\circ} \mathrm{C}$ (Table 4). This is consistent with the weak deactivation of the catalyst at long use (see below). The depleted deposition of

Table 4 Carbon deposition (\%, elemental analysis by EDX) on the surface of mesoporous $\gamma$-alumina catalyst at different temperatures and LHSV values

\begin{tabular}{lll}
\hline Temperature $\left({ }^{\circ} \mathrm{C}\right)$ & LHSV $\left(\mathrm{h}^{-1}\right)$ & \\
\cline { 2 - 3 } & 2 & 4 \\
\hline 150 & 0 & 0 \\
175 & 0 & 0 \\
200 & 0 & 0 \\
225 & 0 & 0 \\
250 & 0 & 0 \\
300 & 0.65 & 0.22 \\
350 & 1.44 & 1.13 \\
\hline
\end{tabular}


coke or carbonaceous-based products at the surface of SAGMA catalyst indicates that among the two reported mechanisms, the most probable is the second: post-reaction of produced propene to form additional benzene [71]. Cumene is completely converted into benzene by additional isomerization and polymerization of propyne (or it fragments). This can be directly explained by the high acidity of the catalyst, due to the presence of graphitized chloride on alumina but also the strong ability of $\mathrm{AlCl}_{3}$ (acting as an isomerization catalyst) to polymerize and re-arrange propyne to benzene [38,55]. The mesoporous structure of self-chlorinated $\gamma$-alumina (bearing strong Lewis and Brønsted acid sites) is effective for regeneration and combination of formed species to benzene at low values of LHSV.

These different results allow considering SAGMA catalyst as a very promising and powerful material for cumene conversion but also other catalytic reactions, such as the thermal and/or catalytic cracking of heavy petroleum cuts (to produce heavy gas oil) and the thermal degradation of polymeric compounds. Biodiesel production by transesterification of fatty acids and dehydration of ethanol is currently under investigation using SAGMA material.

Sazegar et al. [54] reported lower cumene conversion for protonated Al-grafted mesostructured silica nanoparticles; conversion increased from 20 to $58 \%$ when increasing the temperature from 50 to $400{ }^{\circ} \mathrm{C}$; the reaction is relatively selective at low temperature for synthesizing $\alpha$-methylstyrene (and side products of long C chains) (dehydrogenation route), while at higher temperatures both dealkylation and dehydrogenation routes are activated (at the expense of a loss in selectivity). Cumene conversion was enhanced up to $94-97 \%$ by incorporation of $\mathrm{Pt}$ into the catalyst [72]. Table 2 reports some literature data on cumene conversion; these results confirm the promising potential of SAGMA catalyst compared to alternative materials in terms of both efficiency and selectivity.

The issues on repeatability of catalytic tests and reproducibility of catalyst synthesis have been addressed preparing different stocks of materials. The tests performed on freshly prepared catalysts are reported in the Additional Material Section (see Tables AM1 and AM2, for LHSV 2 and $4 \mathrm{~h}^{-1}$, respectively). As a general comment, freshly prepared catalyst showed a slightly higher catalytic activity than for aged catalyst; the variation was less than $3.5 \%$. The repeatability in catalytic tests was very high (variation less than $1 \%$ ). However, the selectivity for benzene synthesis was decreased: the comparison of selectivity coefficients under LHSV $4 \mathrm{~h}^{-1}$ shows that at low temperature (below $225^{\circ} \mathrm{C}$ ) the freshly prepared catalyst has a lower selectivity for benzene with a substantial production of ethylbenzene. The analysis of textural properties on the second stock of catalyst showed an increase in the specific surface area and a decrease in the average pore size (from 7.8 to $5 \mathrm{~nm}$, see Additional Material Section).

\section{Deactivation studies}

Another important parameter in the evaluation of the effectiveness of a catalytic system is the analysis of the deactivation of the catalyst that can be due to several reasons: (a) change in the acidity of the surface, (b) poisoning of the surface by deposition of sub-products (coke and carbonaceous products, side products, etc.), (c) physical degradation and destructuration of the support. Figure 11 shows the evolution of the catalytic efficiency at long use
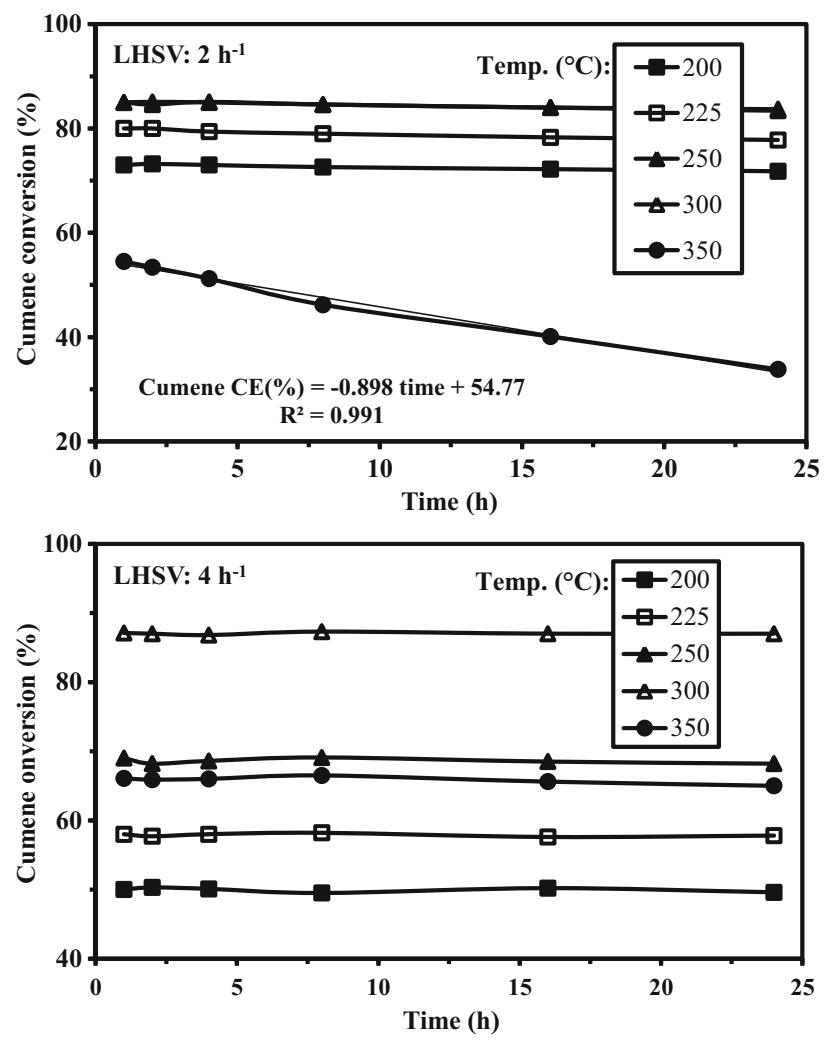

Figure 11 Study of the deactivation of mesoporous $\gamma$-alumina catalyst - effect of reaction time, LHSV, and temperature on cumene conversion efficiency (\%). 
(running test over $24 \mathrm{~h}$ ) for different temperatures and at LHSV 2 and $4 \mathrm{~h}^{-1}$. For the highest LHSV value (i.e., $4 \mathrm{~h}^{-1}$ ), the conversion efficiency was not affected by reaction time, regardless of the reaction temperature (between 200 and $350{ }^{\circ} \mathrm{C}$ ). This trend was roughly the same than for the lowest LHSV (i.e., $2 \mathrm{~h}^{-1}$ ): the reaction time does not affect the conversion efficiency of cumene between 200 and $300{ }^{\circ} \mathrm{C}$; however, at higher temperature (i.e., $350{ }^{\circ} \mathrm{C}$ ) the sorption efficiency progressively decreases (linear variation). The singular behavior of the system at high temperature and low HLSV (i.e., longer contact time of the reagents and products with the catalytic phase) can be explained by the dual effects of strong surface acidity of the catalyst and partial (but progressive) cracking of sorbed and produced species into coke (and carbonaceous-based materials) that could poison the acidic sites at the surface of the catalyst. High temperature, long contact time, and strong reactive surface sites may explain this depreciable effect that may affect conversion efficiency. Actually, the poisoning of the surface is not observed under selected experimental conditions. This is confirmed also by the characterizations of the catalyst (before and after reaction and calcination) through EDX analysis, elemental analysis (i.e., carbon deposition as coke-based coating), or TPD. The poisoning of the catalyst may result from several causes including the formation of coke at the surface of the catalyst. The evolution of the $C$ content (weight percentage, measured by SEM-EDX analysis) was evaluated on a long-term kinetic experiment of cumene conversion under optimum conditions (i.e., T $350{ }^{\circ} \mathrm{C}$ and LHSW 2). C content increases accordingly 0.28 , $0.67,1.15,1.37$, and $1.47 \%$, while reaction time increases from 1, to $4 \mathrm{~h}, 8 \mathrm{~h}, 16 \mathrm{~h}$, and $24 \mathrm{~h}$, respectively. This means that even after $24 \mathrm{~h}$ of reaction the coke formation and deposition at the surface of the catalyst remained very low (below 1.5\% in weight). This may contribute to the slight decrease in catalytic performance. It appears that the chlorination of SAGMA catalyst is appreciably stable even after severe experimental conditions of use. The comparison of the performances of different materials for cumene conversion showed that the key parameter is the acidity of the catalyst rather than its specific surface area and porosity (which could be affected by the deposition of sub-products): the possible deposition of coke-based materials after reaction and calcination is supposed to decrease the specific surface area, with derived effect on catalytic activity. However, cumene conversion does not appear to be hardly affected by porous characteristics.

It could be observed that the prepared alumina catalyst possessed stable catalytic activity toward cumene conversion at moderate temperatures $\left(200-300{ }^{\circ} \mathrm{C}\right)$ for the both applied LHSVs. The only observed deactivation result was recorded at $350{ }^{\circ} \mathrm{C}$ and LHSV 2 where the activity was reduced from 54.5 to $\sim 34$ after $24 \mathrm{~h}$, which can be discussed by the role of both the strong surface acidity of alumina and the low LHSV; the strong acid sites are sufficient to facilitate the dealkylation of cumene (as noted at lower temperatures), while low LHSV offered long residence time for cumene and/or its defragment species on the alumina catalyst that let to further cracking of the species into fine coke on the catalyst surface at this high temperature. In the case of Algrafted mesostructured silica nanoparticles, the progressive decrease in the conversion efficiency of cumene required reactivation steps every $24 \mathrm{~h}$ of use [54]; the stability of the catalyst was considerably improved by incorporation of $\mathrm{Pt}$ in the structured material [72]: conversion efficiency hardly varied over 100 -h operating time.

\section{Conclusions}

A new economic route was designed for the direct preparation and surface acidification of mesoporous alumina at moderate temperatures, under inert atmosphere. In the first step, powdered $\mathrm{AlCl}_{3}$ nanorods are produced by dehydration of $\mathrm{AlCl}_{3}$ solution at $100{ }^{\circ} \mathrm{C}$ in the presence of petroleum wax acting as a capping agent. In the second step, the oxidation of formed nanorods with under air stream at $300{ }^{\circ} \mathrm{C}$ allows producing micron-sized mesoporous $\gamma$-alumina (SAGMA). The self-acidification of $\gamma$-alumina during its preparation was accomplished by recycling the "chlorides" released in the closed reactor during the oxidation of $\mathrm{AlCl}_{3}$-nanorods into alumina. The bonded chloride to $\gamma$-alumina was detected by EDX analysis, while pyridine adsorption and cumene conversion were applied to study the nature and strength of the surface acidity. The selfacidified (chlorinated) $\gamma$-alumina prepared by this method exhibited both strong Lewis and Brønsted acidic properties: immobilized Lewis acid sites were higher in terms of both strength and density at 
temperatures higher than $500{ }^{\circ} \mathrm{C}$. The density of acid sites at the surface of SAGMA is higher than $1.7 \mathrm{mmol} \mathrm{g}^{-1}$. The identification and the relative strength of these acidic groups were determined by temperature-programmed desorption (TPD), FTIR analysis, and pyridine sorption. Several techniques (nitrogen adsorption/desorption, SEM, TEM, etc.) have been used for the characterization of dendritic leaflike crystals supported on mesoporous-structured material (pore size close to $7.8 \mathrm{~nm}$ with specific surface area close to $230 \mathrm{~m}^{2} \mathrm{~g}^{-1}$ ).

The application of these SAGMA catalysts for the conversion of cumene into benzene (main product) demonstrated that the preferred pathway consists of the dealkylation pathway: the reaction is relatively specific and selective (the products potentially generated through dehydrogenation pathway are not detected). Side products are hardly generated when operating at long contact time (low LHSV) and temperature down to $250{ }^{\circ} \mathrm{C}$. Maximum cumene conversion by SAGMA reached $87 \%$ at $300{ }^{\circ} \mathrm{C}$ and for $\mathrm{LHSV}=4$. However, relatively high conversion yields (close to $80 \%$ ) were also obtained under mild conditions (i.e., $250{ }^{\circ} \mathrm{C}$ and LHSV = 2). SAGMA was also characterized by a relatively high stability as shown by the characterization of the spent material with raw supports but also with long-time use of catalysts (continuous mode for $24 \mathrm{~h}$ ): the degradation of cumene conversion performance is only identified at temperature close to $350{ }^{\circ} \mathrm{C}$ and for long reaction times. The strong acidity of catalyst surface orientated the reaction to prevent the formation of coke/carbonaceous sub-products, which, in turn, together with the stability of acid sites, explains the stability of catalytic performance.

The synthesis of catalysts appears to be globally reproducible: the catalytic activity remains very close in terms of cumene conversion; though freshly prepared catalyst showed a little decrease at high LHSV and low temperature.

\section{Acknowledgements}

This work was financially supported by the Egyptian Petroleum Research Institute (EPRI), Egypt. This work is specially dedicated to the memory of Prof. Dr. Ahmed Donia.

\section{Compliance with ethical standards}

Conflicts of interest All authors declare that they have no conflict of interest.

Electronic supplementary material: The online version of this article (https://doi.org/10.1007/s108 53-018-03270-1) contains supplementary material, which is available to authorized users.

\section{References}

[1] Nakamura I, Sunada K, Fujimoto K (1997) Low temperature hydrocracking of paraffinic hydrocarbons over hybrid catalysts. Stud Surf Sci Catal 106:361-370

[2] Nakamura I, Zhang A, Fujimoto K (1997) Selective synthesis of methylcyclopentane from cyclohexane using Ptzeolitehybrid catalyst. Stud Surf Sci Catal 106:561-566

[3] Barakov RY, Shcherban ND, Yaremov PS et al (2016) Effect of the structure and acidity of micro-mesoporous alumosilicates on their catalytic activity in cumene cracking. Theor Exp Chem 52:212-220

[4] Belhakem A, Bengueddach A (2006) Cumene cracking on modified mesoporous material type MCM-41. Turk J Chem 30:287-295

[5] Hosseinpour N, Mortazavi Y, Khodadadi AA (2014) Cumene cracking activity and enhanced regeneration of FCC catalysts comprising $\mathrm{HY}$-zeolite and $\mathrm{LaBO}_{3}(\mathrm{~B}=\mathrm{Co}, \mathrm{Mn}$, and $\mathrm{Fe}$ ) perovskites. Appl Catal A 487:26-35

[6] Hino M, Kurashige M, Matsuhashi H, Arata K (2006) A solid acid of tungsta-niobia more active than aluminosilicates for decompositions of cumene, ethylbenzene, and toluene. Appl Catal A 310:190-193

[7] Smirnova MY, Toktarev AV, Ayupov AB, Echevsky GV (2010) Sulfated alumina and zirconia in isobutane/butene alkylation and n-pentane isomerization: catalysis, acidity, and surface sulfate species. Catal Today 152:17-23

[8] Samantaray SK, Parida K (2004) Effect of anions on the textural and catalytic activity of titania-silica mixed oxide. J Mater Sci 39:3549-3562. https://doi.org/10.1023/B:JMSC. $0000030706.75013 .3 \mathrm{~b}$

[9] Kang NY, Woo SI, Lee YJ, Bae J, Choi WC, Park Y-K (2016) Enhanced hydrothermal stability of ZSM-5 formed from nanocrystalline seeds for naphtha catalytic cracking. J Mater Sci 51:3735-3749. https://doi.org/10.1007/s10853015-9691-8

[10] Mihalyi RM, Lonyi F, Beyer HK et al (2013) n-Heptane hydroconversion over nickel-loaded aluminum- and/or 
boron-containing BEA zeolites prepared by recrystallization of magadiite varieties. J Mol Catal A: Chem 367:77-88

[11] Moreno S, Kou RS, Molina R, Poncelet G (1999) Al-, Al, $\mathrm{Zr}$-, and Zr-pillared montmorillonites and saponites: preparation, characterization, and catalytic activity in heptane hydroconversion. J Catal 182:174-185

[12] Thanh Khoa P, Busca G (2015) Ethanol dehydration on silica-aluminas: active sites and ethylene/diethyl ether selectivities. Catal Commun 68:110-115

[13] Yadav R, Sakthivel A (2014) Silicoaluminophosphate molecular sieves as potential catalysts for hydroisomerization of alkanes and alkenes. Appl Catal A 481:143-160

[14] Mostafa MS, Bakr A-SA, El Naggar AMA, Sultan E-SA (2016) Water decontamination via the removal of $\mathrm{Pb}$ (II) using a new generation of highly energetic surface nanomaterial: $\mathrm{co}^{+2} \mathrm{Mo}^{+6}$ LDH. J Colloid Interface Sci 461:261-272

[15] Bakr AA, Mostafa MS, Sultan EA (2016) Mn(II) removal from aqueous solutions by $\mathrm{Co} / \mathrm{Mo}$ layered double hydroxide: kinetics and thermodynamics. Egypt J Pet 25:171-181

[16] Grant SM, Jaroniec M (2012) Effect of acid concentration on pore size in polymer-templated mesoporous alumina. J Mater Chem 22:86-92

[17] Wang Z, Du H, Gong J, Yang S, Ma J, Xu J (2014) Facile synthesis of hierarchical flower-like gamma-AlOOH films via hydrothermal route on quartz surface. Colloids Surf A 450:76-82

[18] Zhang H, Hang Y, Qin Y, Yang J, Wang B (2014) Synthesis and characterization of sol-gel derived continuous spinning alumina based fibers with silica nano-powders. J Eur Ceram Soc 34:465-473

[19] Wu W, Wan Z, Chen W, Yang H, Zhang D (2014) A facile synthesis strategy for structural property control of mesoporous alumina and its effect on catalysis for biodiesel production. Adv Powder Technol 25:1220-1226

[20] Tang X, Yu Y (2015) Electrospinning preparation and characterization of alumina nanofibers with high aspect ratio. Ceram Int 41:9232-9238

[21] Zhang H, Zhang Y, Wang B, Yang J (2015) Preparation and characterization of continuous alumina based fiber reinforced with orientated mullite whisker. Chem Eng J 268:109-115

[22] Jeon H, Ahn SH, Kim JH, Min YJ, Lee KB (2011) Templated synthesis of mesoporous aluminas by graft copolymer and their $\mathrm{CO}_{2}$ adsorption capacities. $\mathrm{J}$ Mater Sci 46:4020-4025. https://doi.org/10.1007/s10853-011-5330-1

[23] Webber J, Zorzi JE, Perottoni CA, Moura e Silva S, Cruz $\mathrm{RCD}$ (2016) Identification of alpha- $\mathrm{Al}_{2} \mathrm{O}_{3}$ surface sites and their role in the adsorption of stearic acid. J Mater Sci 51:5170-5184. https://doi.org/10.1007/s10853-016-9819-5
[24] Bhat A, Megeri GB, Thomas C et al (2015) Adsorption and optimization studies of lead from aqueous solution using $\gamma$ Alumina. J Environ Chem Eng 3:30-39

[25] Srivastav A, Srivastava VC (2009) Adsorptive desulfurization by activated alumina. J Hazard Mater 170:1133-1140

[26] Kraleva E, Palcheva R, Dimitrov L, Armbruster U, Brueckner A, Spojakina A (2011) Solid acid catalysts for dehydration of glycerol to acrolein in gas phase. J Mater Sci 46:7160-7168. https://doi.org/10.1007/s10853-011-5379-x

[27] Zhou S, Zhou Y, Shi J, Zhang Y, Sheng X, Zhang Z (2015) Synthesis of Ce-doped mesoporous gamma-alumina with enhanced catalytic performance for propane dehydrogenation. J Mater Sci 50:3984-3993. https://doi.org/10.1007/s1 0853-015-8954-8

[28] Zhang Y, Liang H, Zhao CY, Liu Y (2009) Macroporous alumina monoliths prepared by filling polymer foams with alumina hydrosols. J Mater Sci 44:931-938. https://doi.org/ 10.1007/s10853-008-3189-6

[29] Zhu Z, Sun H, Liu H, Yang D (2009) PEG-directed hydrothermal synthesis of alumina nanorods with mesoporous structure via AACH nanorod precursors. J Mater Sci 45:46. https://doi.org/10.1007/s10853-009-3886-9

[30] Nemanashi M, Noh J-H, Meijboom R (2018) Dendrimers as alternative templates and pore-directing agents for the synthesis of micro- and mesoporous materials. J Mater Sci 53:12663-12678. https://doi.org/10.1007/s10853-018-2 527-6

[31] Giraldo SA, Centeno A (2008) Isomerization and cracking under HDS conditions using gamma-alumina modified with boron as catalysts support. Catal Today 133:255-260

[32] Vu XH, Bentrup U, Hunger M, Kraehnert R, Armbruster U, Martin A (2014) Direct synthesis of nanosized-ZSM-5/SBA15 analog composites from preformed ZSM-5 precursors for improved catalytic performance as cracking catalyst. J Mater Sci 49:5676-5689. https://doi.org/10.1007/s10853-014-828 $7-\mathrm{z}$

[33] Li Q, Zhang X, Xiao M, Liu Y (2013) Alumina incorporated with mesoporous carbon as a novel support of Pt catalyst for asymmetric hydrogenation. Catal Commun 42:68-72

[34] Kumaran GM, Garg S, Soni K et al (2008) Synthesis and characterization of acidic properties of Al-SBA-15 materials with varying $\mathrm{Si} / \mathrm{Al}$ ratios. Microporous Mesoporous Mater 114:103-109

[35] Sumiya S, Fujiwara J, Oumi Y, Sadakane M, Sano T (2011) Incorporation of highly dispersed aluminum into inner surfaces of supermicroporous silica using anionic surfactant. J Porous Mater 18:493-500

[36] Bae JW, Kim S-M, Lee Y-J, Lee M-J, Jun K-W (2009) Enhanced Fischer-Tropsch activity on $\mathrm{Co} / \mathrm{P}-\mathrm{Al}_{2} \mathrm{O}_{3}$ catalyst: 
effect of phosphorous content. Catal Commun 10:1358-1362

[37] Yan B, Guo M (2013) Photoluminescent hybrid alumina and titania gels linked to rare earth complexes and polymer units through coordination bonds. Inorg Chim Acta 399:160-165

[38] Clet G, Goupil JM, Szabo G, Cornet D (1999) Chlorinated alumina as an alkylation catalyst: influence of superficial HCl. J Mol Catal A: Chem 148:253-264

[39] Clet G, Goupil JM, Szabo G, Cornet D (2000) Chlorinated alumina as an alkylation catalyst: influence of acidity moderators. Appl Catal A 202:37-47

[40] Moreno-Bravo M, Hernandez-Luna M, Alcaraz-Cienfuegos J, Rosas-Aburto A (2003) Fluorinated alumina for benzene propylation: reaction scheme and heterogeneity of the acid surface. Appl Catal A 249:35-52

[41] Kozhevnikov IV (1998) Catalysis by heteropoly acids and multicomponent polyoxometalates in liquid-phase reactions. Chem Rev 98:171-198

[42] Macho V, Jurecek L, Komora L, Jureckova E, Komorova E (2003) Gamma-alumina modified by acidification as an acidic catalyst for petrochemical processes. Pet Coal 45:49-53

[43] Sarbak Z (1997) Acidity, cumene conversion and thiophene hydrodesulfurization over alumina and surface modified aluminas. Appl Catal A 159:147-157

[44] Ivanova II, Montouillout V, Fernandez C, Marie O, Gilson JP (2003) Cumene transformations over mordenite catalysts: a C-13 MAS NMR study. Microporous Mesoporous Mater 57:297-308

[45] Xu N, Liu Z, Bian S, Dong Y, Li W (2016) Template-free synthesis of mesoporous gamma-alumina with tunable structural properties. Ceram Int 42:4072-4079

[46] Dabbagh HA, Yalfani M, Davis BH (2005) An XRD and Fourier-transformed infrared spectroscopy investigation of single and mixed gamma-alumina and thorium oxide. $\mathrm{J}$ Mol Catal A: Chem 238:72-77

[47] Chuah GK, Jaenicke S, Xu TH (2000) The effect of digestion on the surface area and porosity of alumina. Microporous Mesoporous Mater 37:345-353

[48] Kytokivi A, Lindblad M, Root A (1995) IR and ${ }^{1} \mathrm{H}$ NMR studies on the adsorption of gaseous hydrogen chloride on g-alumina, J. Chem. Soc. Faraday Trans 91:941-948

[49] Guillaume D, Gautier S, Alario F, Deves JM (1999) Relation between acid and catalytic properties of chlorinated gammaalumina-a P-31 MAS NMR and FTIR investigation. Oil Gas SciTechnol 54:537-545

[50] Lefrancois M, Malbois G (1971) The nature of the acidic sites on mordenite: characterization of adsorbed pyridine and water by infrared study. J Catal 20:350-358
[51] Thibault-Starzyk F, Vimont A, Gilson JP (2001) 2D-COS IR study of coking in xylene isomerisation on H-MFI zeolite. Catal Today 70:227-241

[52] Hosseinpour N, Khodadadi AA, Mortazavi Y, Bazyari A (2009) Nano-ceria-zirconia promoter effects on enhanced coke combustion and oxidation of $\mathrm{CO}$ formed in regeneration of silica-alumina coked during cracking of triisopropylbenzene. Appl Catal A 353:271-281

[53] Sakthivel A, Badamali SK, Selvam P (2000) para-Selective t-butylation of phenol over mesoporous H-AlMCM-41. Microporous Mesoporous Mater 39:457-463

[54] Sazegar MR, Jalil AA, Triwahyono S et al (2014) Protonation of Al-grafted mesostructured silica nanoparticles (MSN): acidity and catalytic activity for cumene conversion. Chem Eng J 240:352-361

[55] Mao HH, Li BS, Yue LW, Wang LY, Yang JH, Gao XX (2011) Aluminated mesoporous silica-pillared montmorillonite as acidic catalyst for catalytic cracking. Appl Clay Sci 53:676-683

[56] Bonelli B, Palmero P, Lomello F, Armandi M, Lombardi M (2010) Study of the effect of prolonged magnetic stirring on the physico-chemical surface properties of nanometric transition alumina. J Mater Sci 45:6115-6125. https://doi.org/10. 1007/s10853-010-4698-7

[57] Wang CM, Wang P, Wang H, Zhao BY, Zhu YX, Xie YC (2005) Sucrose-assisted preparation of high surface area gamma-alumina and influence of sucrose content on its textural properties. Chin J Catal 26:797-802

[58] Dabbagh HA, Rasti E, Yalfani MS, Medina F (2011) Formation of gamma-alumina nanorods in presence of alanine. Mater Res Bull 46:271-277

[59] Pai RV, Pillai KT, Pathak S et al (2012) Synthesis of mesoporous gamma-alumina by sol-gel process and its characterization and application for sorption of $\mathrm{Pu}(\mathrm{IV})$. J Sol-Gel Sci Technol 61:192-196

[60] Mrabet D, Vu M-H, Kaliaguine S, Do T-O (2017) A new route to the shape-controlled synthesis of nano-sized gamma-alumina and $\mathrm{Ag}$ /gamma-alumina for selective catalytic reduction of NO in the presence of propene. J Colloid Interface Sci 485:144-151

[61] Sachse A, Gerardin C, Delahay G, Belamie E, Kostov KL, Alonso B (2017) A facile strategy for the preparation of highly mesoporous gamma-alumina. Eur J Inorg Chem. https://doi.org/10.1002/ejic.201700175:1516-1519

[62] Mei J, Shao Y, Lu S, Ma Y, Ren L (2018) Synthesis of $\mathrm{Al}_{2} \mathrm{O}_{3}$ with tunable pore size for efficient formaldehyde oxidation degradation performance. J Mater Sci 53:3375-3387. http s://doi.org/10.1007/s10853-017-1795-X

[63] Huang T, Meng F, Qi L (2010) Controlled synthesis of dendritic gold nanostructures assisted by supramolecular 
complexes of surfactant with cyclodextrin. Langmuir 26:7582-7589

[64] Fingas M, Fieldhouse B (2004) Formation of water-in-oil emulsions and application to oil spill modelling. J Hazard Mater 107:37-50

[65] Kentish S, Wooster TJ, Ashokkumar A, Balachandran S, Mawson R, Simons L (2008) The use of ultrasonics for nanoemulsion preparation. Innov Food Sci Emerg Technol 9:170-175

[66] Dabbagh HA, Shahraki M (2013) Mesoporous nano rod-like gamma-alumina synthesis using phenol-formaldehyde resin as a template. Microporous Mesoporous Mater 175:8-15

[67] Li H, Lu H, Wang S, Jia J, Sun H, Hu X (2009) Preparation of a nano-sized $\alpha-\mathrm{Al}_{2} \mathrm{O}_{3}$ powder from a supersaturated sodium aluminate solution. Ceram Int 35:901-904

[68] Parida KM, Acharya M, Mishra T (2000) Tungstate-modified aluminium phosphate-1. Preparation, characterisation and catalytic activity towards alcohol and cumene conversion reactions. J Mol Catal A: Chem 164:217-223

[69] Corma A, Fierro JLG, Montanana R, Tomas F (1985) On the mechanism of cumene dealkylation - the interaction of cumene molecules on silica-alumina surfaces. J Mol Catal 30:361-372

[70] Balandin AA (1962) The multiplet theory of catalysis. Structural factors in catalysis. Russ Chem Rev 31:589-614

[71] Jian PM, Wang QY, Zhu C, Xu YH (1992) Alkylation of benzene with propene to produce cumene over a nickel gamma-alumina catalyst. Appl Catal A 91:125-129

[72] Sazegar MR, Triwahyono S, Jalil AA, Mukti RR, Mohaghegh SMS, Aziz M (2015) High activity of aluminated bifunctional mesoporous silica nanoparticles for cumene hydrocracking and measurement of molar absorption coefficient, New. J Chem 39:8006-8016

[73] Ordomsky VV, Ivanova II, Knyazeva EE, Yuschenko VV, Zaikovskii VI (2012) Cumene disproportionation over micro/mesoporous catalysts obtained by recrystallization of mordenite. J Catal 295:207-216

[74] Parida KM, Acharya M, Samantaray SK, Mishra T (1999) Studies on anion promoted titania. 1: preparation, characterization, and catalytic activity toward alcohol and cumene conversion reactions of phosphated titania. J Colloid Interface Sci 217:388-394 